\title{
RESPIRAR Y CONSPIRAR: REPENSANDO LA ANSIEDAD COMO RESISTENCIA DE COMBATE FEMINISTA
}

Marta Pérez Arias

Primera supervisora:

Carmen Gregorio Gil

Universidad de Granada

Segunda Supervisora:

Magdalena Górska

Utrecht University

Universidad de Granada 


\section{RESPIRAR Y CONSPIRAR: REPENSANDO LA ANSIEDAD COMO RESISTENCIA DE COMBATE FEMINISTA}

Marta Pérez Arias

Primera supervisora:

Carmen Gregorio Gil

Universidad de Granada

\section{Segunda Supervisora:}

Magdalena Górska

Utrecht University 


\section{RESUMEN}

En esta tesis de master me centra en las experiencias de ansiedad, observándolas como una resistencia combativa frente al orden del poder estructural. La ansiedad es un fenómeno mundial, tratado a nivel médico y psicológico; no obstante, esta tesis de máster propone un nuevo planteamiento de la misma, entendiéndola desde un marco político y social que busca combatir las nociones hegemónicas imbricadas en su definición. Así, se fundamenta por su carácter exploratorio e interpretativo, ya que no es mi deseo hallar una verdad absoluta y universalizable: cada experiencia de ansiedad es única, diversa y está sujeta a la subjetividad de cada persona. Más bien, el objetivo principal de esta investigación busca deconstruir las narrativas hegemónicas con la intención de visibilizar y ofrecer un espacio de encuentro de nuestras propias vulnerabilidades, hasta ahora silenciadas por las operaciones de poder neoliberales y capitalistas.

Como metodología clave a la hora de observar estas experiencias de ansiedad, la investigación cuenta con tres relatos de mujeres abordando creativamente sus experiencias personales. Así, propongo la escritura creativa como método válido para explorar y observar las experiencias subjetivas, con la intención de repensar estas experiencias encarnadas y finalmente plantearlas como mecanismo de combate alternativo a las operaciones del poder estructural. Además, politizar dichas experiencias resulta un ejercicio crucial para repensar la ansiedad desde una perspectiva feminista, por lo que finalmente observaré los tres relatos de ansiedad mediante un ejercicio de "close reading", o lectura de cerca. Este trabajo pretende, por tanto, partir de nuestra experiencia, pero también de nuestros padecimientos y dolores, para problematizar las violencias estructurales que nos atraviesan diariamente y plantear estrategias feministas que nos ayuden a respirar día tras día.

Palabras clave: ansiedad, subjetividad, feminismo, escritura creativa, vulnerabilidad, respiración. 


\begin{abstract}
This master's thesis focuses on anxiety experiences, observing them as a combat resistance against the order of structural power. Anxiety is a worldwide phenomenon, treated at a medical and psychological level; however, this Master's thesis proposes a new approach to it, understanding it from a political and social framework that seeks to combat the hegemonic notions embedded in its definition. Thus, it is based on its exploratory and interpretative character, since it is not my desire to find an absolute and universal truth: each experience of anxiety is unique, diverse and subject to the subjectivity of each person. Rather, the main objective of this research seeks to deconstruct hegemonic narratives with the intention of making visible and offering a meeting place for our own vulnerabilities, hitherto silenced by neoliberal and capitalist power operations.

As a key methodology when observing these anxiety experiences, the research focuses on three tales that creatively address personal experiences. Thus, I propose creative writing as a valid method to explore and observe subjective experiences, with the intention of rethinking these embodied experiences and finally pose them as an alternative combat mechanism to the operations of structural power. In addition, politicize these experiences turns out to be a crucial exercise to rethink anxiety from a feminist perspective, so I will be observing these three stories of anxiety through an exercise of "close reading". This work aims, therefore, to start from our experience, but also from our sufferings and pains, to problematize the structural violence that crosses us daily and to propose feminist strategies that help us breathe day after day.
\end{abstract}

Keywords: anxiety, subjectivity, feminism, creative writing, vulnerability, breathing. 


\section{ÍNDICE}

INTRODUCCIÓN. "BREATH ME”.

1. Metodología Feminista: La Perspectiva del Cuerpo y La Escritura CREATIVA COMO PRÁCTICA LIBERADORA.

1.1. Los conocimientos situados: la labor de la experiencia como fuente de producción de conocimiento.

1.2. La escritura creativa como herramienta metodológica.

1.3. Narración autoetnográfica: la perspectiva del cuerpo.

2. CONCEPTUALIZANDO LA ANSIEDAD: UnA APROXIMACión DESDE LOS Estudios DE LOS AFECTOS.

2.1. El imperativo de la felicidad: sujetos ideales y sujetos dispensables.

2.2. ( $R e)$ Dirigir a través de las políticas del miedo y del fracaso: las operaciones del poder estructural.

2.3. Biopolíticas del poder y resistencias performativas: una aproximación a la respiración de combate.

3. Relatos DESDE la SUbAlteRnidAD: LA ANSIEDAD COMO RESISTENCIA DE COMBATE.

3.1. Contexto socio-político: estigmatización y lenguaje.

3.2. No estamos locas, estamos hartas: lazos sororos y dimensión de género.

3.3. Relatos de ansiedad: nuevas alternativas de resistencias combativas.

4. ESCRIBIR PARA POLITIZAR, POLITIZAR PARA TRANSFORMAR.

4.1. Relato uno: "Cicatrices: VIII"

4.2. Relato dos: "Terrores Nocturnos" 50

4.3. Relato tres.

4.4. Reflexiones feministas: El alcance de los relatos. 55

CONCLUSIONES: COLECTIVIZAR los MALESTARES, COMPARTIR NUESTRAS 
“I just... I don't like being alone. I'm not good on my own. My head gets so loud and nothing syncs up. I start thinking about my thinking and getting lost in the details of nothing. Nothing can pull me out of it."

(Juice Ortiz, Sons of Anarchy). ${ }^{1}$.

\footnotetext{
${ }^{1}$ Traducción: "Es que... no me gusta estar solo. No sé estar solo. Oigo muchas voces en mi cabeza y nada tiene sentido. Empiezo a pensar en no pensar y acabo perdiéndome en los detalles de nada. Nada puede sacarme de ahí" (Juice Ortiz, Sons of Anarchy)
} 


\section{INTRODUCCIÓN. “BREATH ME” 2}

Decía en una presentación en Madrid $^{3}$, hace muy poco, que escribir sobre ansiedad con el corazón agarrotado y un sentimiento de asfixia que no parece querer desvanecerse no es tarea sencilla; menos aun cuando ese malestar (llamémoslo malestar) te lo provoca, en su mayoría, una institución como la Academia. Este trabajo nació de la incertidumbre, del dolor; pero también del dolor de otras, de aprender a reconocerme en ellas y del camino que juntas hemos recorrido, pues es en las experiencias dolorosas en las que encontramos el sentido para hablar, ya que nos permiten identificar las motivaciones personales y cargas afectivas (Das, 2008: 276). A la cabeza se me viene el síndrome de la impostora como visitante asiduo, o el tan conocido bloqueo que produce que tus dedos no sean capaces de acariciar un teclado. No obstante, esta investigación también nace de las incasables lecturas, aunque más aún, de aquellas que sin alejarse de la teoría llamaban a la práctica y a la vida ordinaria. Sara Ahmed, bell hooks ${ }^{4}$, Ann Cvetkovich y Laurent Berlant, entre otras, son algunas de las académicas que me han ayudado en este proceso de identificación, ya que sus trabajos me hicieron sentir especialmente motivada.

Así, esta tesis de máster se fundamenta por su carácter exploratorio e interpretativo, por lo que en ningún momento trataré de obtener respuestas sobre un fenómeno tan amplio y difícil de abarcar como las experiencias de ansiedad. Además, no pretendo ofrecer una respuesta universal a su padecimiento, sino más bien observar un malestar concreto, personal y subjetivo, para más adelante repensar y conversar desde una perspectiva feminista sobre estas vivencias, atendiendo particularmente a su dimensión cultural y social (más que desde una perspectiva médica). Para observar este objeto de estudio, he creído conveniente entender el feminismo como un movimiento interseccional que se centra no sólo en el patriarcado o el racismo, sino en las estructuras de poder que nos invisibilizan y discriminan día tras día, de esta forma siguiendo la propuesta de Ahmed (2017: 29) de concebir el feminismo como una forma de retar lo universal.

\footnotetext{
${ }^{2}$ El título de este apartado significa literalmente "Respírame". Hago referencia a una canción de la artista Sia en la que habla de su experiencia con la ansiedad, pero también al sentido simbólico de la palabra: "respírame", “conóceme". A su vez, está hilado con el símil de la respiración que desarrollaré más adelante.

${ }^{3}$ Más concretamente, en la presentación del libro "Disidencia en el Cuerpo: Perspectivas Feministas" (2019) en la Librería Mujeres de Madrid.

${ }^{4}$ En esta tesis mantengo la decisión de la autora de ser nombrada con letras minúsculas.
} 
Dicho esto, con este trabajo tengo tres ambiciones principales, que podrían leerse como los objetivos principales dentro de esta investigación. La primera de ellas se centra en crear un espacio cómodo y seguro donde compartir estas experiencias invisibilizadas e ignoradas; dar pie a unas voces que también buscan contar su historia. La segunda hace referencia a mi interés en conocer y visibilizar: compartir cómo se siente la ansiedad, pero, sobre todo, cómo condiciona nuestra vida diaria. En este trabajo pretendo, por tanto, visibilizar la experiencia de tres mujeres que sufren ansiedad, analizando sus discursos (en este caso, su escritura creativa) para analizar cómo esas experiencias son consecuencia de las operaciones de poder estructural que nos silencia, invisibiliza y oprime día a día.

En segundo lugar, busco crear un punto de inflexión; quizá, al exponer nuestras vulnerabilidades, abramos caminos alternativos para alentar un proceso de pensamiento crítico donde puedan localizarse otro tipo de dolores y padecimientos: al nombrar mi ansiedad, quizás tú puedas reconocer la tuya. Este deseo no parte de una idea de victimización, si no, como explicaré en el capítulo dos y como he adelantado más arriba, de crear redes de apoyo en las que repensar nuestras vulnerabilidades, aprender a vivir y gestionar los sentimientos que socialmente nos condenan al "fracaso".

Por último, y para mí lo más importante, este trabajo es una forma de conectar con todas aquellas mujeres. Las he visto, me han cuidado, he crecido junto a ellas, y me han enseñado a comprender y repensar la ansiedad de una forma alternativa, combativa y performativa. Esta investigación es mi forma de decirles: os quiero, os apoyo y estoy con vosotras en esto. Juntas podemos conseguirlo.

Con esto en mente, he optado por dos métodos que, por un lado, me ayudarán a subrayar la dimensión simbólica y epistemológica de la ansiedad como concepto, desde los estudios (o teorías) de los afectos (especialmente trabajaré con las obras de Ahmed, Berlant y Cvetkovich) y por otro, me ayudarán a conectar la teoría con la práctica gracias a tres casos de estudio de mujeres cercanas a mí. En primer lugar, he realizado una revisión bibliográfica sobre lo escrito de "ansiedad" en este campo de estudios de los afectos, revisando también teorías que funcionen como herramientas para entender, desde una perspectiva feminista y subjetiva, cómo opera este concepto y su relación con el ámbito social, político y cultural. En segundo lugar y como he mencionado más arriba, el análisis de tres casos de estudio que utilizan la escritura creativa para dialogar sobre

\footnotetext{
${ }^{5}$ Ver capítulo 2 .
} 
experiencias de ansiedad es clave en este trabajo, siempre para observar cómo este malestar se metaboliza a través del cuerpo. Esta escritura creativa, como explicaré en el capítulo dos, supone una estrategia metodológica que me permitirá acercarme a ciertas experiencias vivenciales como las emociones encarnadas o los sentimientos, ya que estos suponen un objeto de estudio difícil de atender por otras metodologías.

La investigación está dividida en cuatro capítulos, donde partiré en un primer momento de lo general para más adelante centrarme en lo específico: en el primer capítulo hablaré en profundidad de la metodología que he decidido usar para este trabajo, aludiendo a su justificación y explorando sus ventajas y límites. Específicamente, propongo una metodología feminista que parte de los conocimientos situados cómo opción válida para la producción de conocimiento, haciendo especial hincapié en la noción de la "experiencia" en Haraway (1988) y Scott (1991), y más adelante proponiendo la escritura creativa como método que me permite observar más a fondo las experiencias de ansiedad.

En el segundo capítulo, realizaré un acercamiento conceptual desde los estudios de los afectos, para comprender en mejor medida cómo operan las dinámicas de poder y qué relación tienen con las experiencias de ansiedad. A su vez, será un acercamiento clave desde los sentimientos, que ponga en valor las experiencias vivenciales del cuerpo y nos permita evaluar otras dinámicas feministas de resistencia frente a las formas de vida que encajan con la norma hegemónica. En este capítulo estaré, en su mayoría, siguiendo el trabajo de Sara Ahmed (2004, 2010 y 2017), aunque también me centraré en conceptos de otras autoras (Berlant, 2011; Górska, 2016 o Cvetkovich, 2012, entre otros), teorías que enlazaré en un diálogo común para elaborar este marco teórico que más tarde emplearé para analizar los relatos de ansiedad. Así, mi intención es otorgar de sentido a la teoría, hablar de aquellas autoras que han conversado acerca de ansiedad, o, por el contrario, de otros conceptos que a su vez puedan ayudarme a elaborar un entendimiento más amplio de este fenómeno.

En el tercer y cuarto capítulo, me centraré en la presentación y contextualización de tres relatos relativos a las experiencias subjetivas de ansiedad, parándome a dialogar en el capítulo tres sobre el contexto socio-político en el que se enmarcan, con el objetivo de hacer entender mejor el marco teórico en el que se desenvuelven. El cuarto capítulo se centra en el análisis de los relatos previamente expuestos. Para ello, utilizo el método de “close reading”, que se refiere a una lectura de cerca, crítica y analítica, para deconstruir los relatos y sacar así la información que se teje entre cada pliegue, cada palabra y cada 
metáfora. Así, finalizo el capítulo con un último apartado que tiene a bien recoger algunas de las claves que tienen en común, para más adelante proceder a las conclusiones y bibliografía de la investigación.

Yo soy la investigadora, la amiga y la confidente, y esta que relato a continuación, es tanto su historia como la mía. 


\section{Metodología Feminista: La PeRsPectiva del CUERPo Y LA ESCRITURA CREATIVA COMO PRÁCTICA LIBERADORA.}

"If we start close to home, we open ourselves out" $"$

(Ahmed, 2017: 19)

$\mathrm{Si}$ algo he aprendido investigando sobre ansiedad, es que dialogar sobre la misma no es un ejercicio que deba realizarse a la ligera. Como mencionaba en la introducción, es necesario disponer de herramientas que nos permitan observar la ansiedad con ojos críticos, que a su vez nos aliente a hacernos preguntas, pero siempre respetando y creando un espacio cómodo para quién se desenvuelva bajo sus dinámicas. Sin embargo, el cómo hablar de un tema tan personal me ha llevado a diversos cuestionamientos; si utilizar entrevistas, grupos de discusión, hacerlo meramente documental, etc. No obstante, tras varios meses de investigaciones y divagaciones, la metodología de esta tesis de máster corresponde a lo que a continuación desarrollaré.

En primer lugar, la revisión de varias obras relacionadas con las teorías de los afectos (Ahmed, 2004; Cvetkovich, 2012 y Berlant, 2011, entre otras) me ayudará a elaborar un marco teórico que me permita analizar tres casos subjetivos de experiencias de ansiedad actuales, siempre teniendo en cuenta que en este trabajo tan sólo puedo rascar la superficie de todo lo que me gustaría.

En segundo lugar, me pregunté de qué otra forma podía observar una experiencia vivencial y del cuerpo siendo fiel a lo que quería retratar en el trabajo (una investigación más personal, desde el cariño y la sororidad), y tras mucho negociar conmigo misma, decidí contar con tres casos de estudio que me dotasen de ciertas pistas para repensar y poner en valor las experiencias de ansiedad. La razón por la que valoré que fueran tres casos de estudio y no un número superior se debe principalmente a dos razones. La primera de ellas, está relacionada con el currículum oculto de la investigación, y es que, al tratar experiencias de ansiedad, una tiene que entender y valorar que no todas las personas en las que has pensado en un primer momento puedan realizar un ejercicio de escritura creativa relatando sus propias experiencias, por una cuestión de bienestar y

\footnotetext{
${ }^{6}$ Traducción personal: "Si empezamos cerca de casa, nos abrimos" (haciendo referencia a que hablar desde nuestra experiencia resulta una tarea más sencilla). (Ahmed, 2017: 19)
} 
autocuidado. Por esto mismo, quiero hacer entender que este trabajo no trata exclusivamente de hablar sobre experiencias de ansiedad, sino de cómo esas experiencias de ansiedad han estado presentes durante la elaboración del mismo, y las propias negociaciones que una tiene que realizar diariamente, donde los tiempos y los espacios se vuelven cruciales y vivenciales. Parte del currículum oculto de este trabajo es, por tanto, proporcionar un espacio seguro donde todas podamos expresarnos con comodidad, y crear diálogos que parten de nuestros cuerpos puede resultar una experiencia dolorosa, por lo que finalmente he contado con aquellas personas que se encontraban con la fuerza y energía suficiente para compartir sus relatos. La segunda de las razones se debe a una cuestión logística: de haber pretendido analizar más de tres relatos en tan poco tiempo y espacio, mi sensación y miedo resultó en que hubiese quedado un ejercicio vago e incompleto. Por esto mismo, contar con tres personas me pareció un número más que suficiente.

No obstante, las tres personas no están ni mucho menos escogidas al azar, ya que corresponden a tres queridas mujeres de mi entorno. Esta decisión, además de aportar un toque más personal a este trabajo, es a su vez un factor importante a tener en cuenta, ya que como explicaré a continuación, la cercanía que compartimos las chicas y yo influirá en la forma que tengan de dialogar conmigo y relatar sus experiencias. De un lado, esta cercanía aporta una perspectiva mucho más íntima, un objetivo que siempre he tenido presente, además de una relación ética y de cuidados que no hubiera sido tan fácil de no poseer una confianza previa. Soy consciente también de los riesgos que esta decisión puede suponer; por ejemplo, que elijan qué información compartir conmigo porque les pueda producir vergüenza (muchas veces, relatar experiencias de dolor es más difícil con personas cercanas que ajenas, por lo que existe la posibilidad de que esto afecte a la información que decidan compartir), pero para mí sigue siendo más importante hacer de este trabajo un lugar cómodo y seguro, que fomente el diálogo para compartir experiencias.

Por todo esto, el trabajo está enfocado desde una perspectiva feminista, aquella que pone en valor las experiencias subjetivas, el empezar en una misma, para abordar cuestiones y retos que no hubieran podido aflorar en una investigación positivista y más cercana al canon de la investigación social (esto es, alejada del sujeto de estudio, objetiva y universal).

En un primer apartado justificaré como método crucial para este trabajo la escritura creativa, que planteo como un lugar de sanación (hooks, 1991), no entendiendo 
la sanación como recuperación o superación, sino, como explicaré en el capítulo dos, como una resistencia combativa y transformativa frente a las normas hegemónicas. En el segundo apartado, reflexionaré un poco más en profundidad de mi posicionalidad entorno a las mujeres que me han prestado un trozo de sus vivencias. Por último, en el tercer apartado hablaré sobre la escritura etnográfica y su relevancia en la elaboración de una perspectiva feminista en esta tesis de máster.

A continuación, pretendo reflexionar sobre la importancia de localizar mi propia posicionalidad, de situarme en relación a las mujeres que estoy leyendo y observando, como un sujeto alternativo que está, a su vez, produciendo conocimiento.

\subsection{CONOCIMIENTOS SITUADOS: LA LABOR DE LA EXPERIENCIA COMO FUENTE DE PRODUCCIÓN DE CONOCIMIENTO.}

La escritura reflexiva, aquella que parte del yo, de nuestros cuerpos, requiere que dediquemos un espacio a situarnos, y más aún, a reconocer nuestro contexto y nuestro entorno, para observar cómo nuestra propia experiencia puede afectar al desarrollo de la investigación. De hecho, la posición que ocupamos en la sociedad, las construcciones sociales y culturales, influencian de igual manera cómo percibimos el mundo (D'Silva, Smith, Della, Potter, Talley \& Best, 2016: 97). Al reconocerme como una investigadora que parte de la parcialidad, mi objetivo no es perseguir una verdad absoluta sobre el tema que investigo, por lo que esta investigación de ninguna forma puede ser aplicable universalmente a otras experiencias, ya que debido al contexto en el que se desarrolla, cada una será diversa y podrá diferir de otras. En su lugar, busco visibilizar y repensar las experiencias que hayan elegido compartir conmigo desde el cuidado y el cariño, siempre dentro de un marco feminista e insterseccional que de algún modo aporte el carácter crítico, político y académico que la investigación requiere. De esta forma, últimamente realizaré un análisis de las piezas elegidas para dialogar sobre ellas y cómo nos afecta la ansiedad en nuestra vida ordinaria.

Haraway (1988: 335) ya hablaba de esta base en su obra, de cómo la parcialidad y no la universalidad es necesaria para reafirmar un conocimiento racional, afirmando que "These are claims on people's lives. I am arguing for the view from a body, always a complex, contradictory, structuring, and structured body, versus the view from above, 
from nowhere, from simplicity" ${ }^{78}$. La autora reivindica muy acertadamente la importancia de posicionarnos en nuestros propios cuerpos, y aprender a tomarlos como punto de partida de toda investigación, rechazando la trascendencia obligatoria que se exige en la investigación para convertirnos en corporalidades parciales que parten en blanco hacia el conocimiento (1988: 577). Por otro lado, y citando a Carmen Gregorio Gil, “...siempre somos parte de lo que estudiamos y, de un modo u otro, al definir las relaciones con lo que estudiamos tomamos postura" (2014: 299).

Este proceso me ha ayudado a entender que, como investigadora, también soy responsable de las historias que cuento, por lo que antes de hacerlo y como bien se desvelará a lo largo del texto, mi propia experiencia de mujer blanca y privilegiada será la voz que narre y analice cada capítulo de este trabajo. No obstante, situarte dentro de un relato no es sólo cuestión de exponer tu nacionalidad o color de piel, sino que tiene que ver con entender que dicha perspectiva estará condicionando desde el primer momento la investigación. No podemos alejarnos de nuestra historia, de nuestras experiencias, sólo podemos aceptarlas y reconocerlas, usarlas como herramientas indispensables en nuestro trabajo. De esta forma, validar y reconocer la experiencia en general, y las experiencias de las mujeres que me ayudan a conformar este trabajo en particular (junto a la mía propia, aunque aparezca de manera indirecta) es una estrategia crucial para el desarrollo de la investigación, que me permitirá poner en valor este concepto como fuente legítima y urgente de producción de conocimiento: ese "partir de nuestros dolores" que me permita observar y problematizar las prácticas neoliberales y patriarcales a las que nos vemos sometidxs.

En cuanto a este respecto, hooks $(1991,11)$ respalda lo siguiente:

"Personal testimony, personal experience, is such fertile ground for the production of liberatory feminist theory because usually it forms the base of our theory-making" 9 .

\footnotetext{
${ }^{7}$ Traducción: "Se trata de pretensiones sobre las vidas de la gente, de la visión desde un cuerpo, siempre un cuerpo complejo, contradictorio, estructurante y estructurado, contra la visión desde arriba, desde ninguna parte, desde la simpleza"

${ }^{8}$ El presente trabajo pretende respetar el idioma de origen de las citas utilizadas siempre que no se disponga de una traducción oficial.

${ }^{9}$ Traducción personal: "El testimonio personal, la experiencia personal, es un suelo fértil para la producción de las teorías feministas liberatorias porque normalmente forma la base de nuestra construcción de la teoría" (Hooks, 1991: 11).
} 
Como decía arriba, en este trabajo utilizo la experiencia como una fuente válida de producción de conocimiento, ya que es "parte del lenguaje cotidiano, está tan imbricada en nuestras narrativas, que parece una futilidad abogar por su expulsión. Sirve como una manera de hablar de lo que ocurrió, de establecer diferencias y similitudes, de decir que se tiene un conocimiento inalcanzable" (Scott, 1992: 72). Precisamente por esto, la experiencia no puede convertirse en algo que demos por sentado, porque de hacerlo estaríamos ignorado una fértil fuente de conocimiento. En consecuencia y desde esta perspectiva, es necesaria una relectura de la misma, analizar su discurso y su creación (siempre reconociendo un conocimiento situado) para llegar a comprender algunos de los problemas que le preocupan a la agenda feminista. Por ello, la experiencia es y requiere de una interpretación, que siempre será política, pues lo que cuenta no resulta en un discurso claro o directo, sino que estará siempre sujeto a disputa (1992: 72).

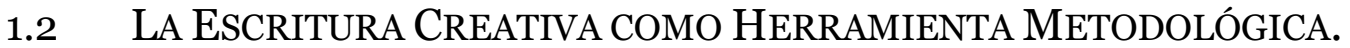

Con trece años, pasaba más de tres horas diarias en un foro online de escritura. La vida real, el colegio, el bullying que sufría por aquel entonces, y sobretodo, la soledad, fueron motores clave en mi proceso de buscar alternativas que me permitiesen evadirme. Y los personajes que escribía (porque escribir sobre una misma puede resultar una experiencia demasiado dolorosa) me ayudaron a sobrellevar la ansiedad y el estrés. No obstante, no fui consciente de cuánto había dado por sentada la escritura cuando me decidí a enfocar esta investigación en torno a las experiencias de ansiedad. Para mí, escribir en momentos de necesidad siempre ha sido algo que ha estado ahí; una vía de escape, un agujero en la pared. Escribir es un proceso de descubrimiento cuyo objetivo es animar a encontrar voz propia (Richardson, 1994: 936). Por otro lado, Ahmed (2010; 200) decía que las palabras son capaces de hacer cosas, aunque no sepamos descifrar exactamente el qué: las palabras pueden ayudarnos a comprender el mundo en el que vivimos. Por ello, en este trabajo la escritura ostenta un papel fundamental.

Así aprendí que la escritura es un arma, y como arma, una ha de aprender a usarla de forma eficaz.

En 2012, Ann Cvetkovich publicaba su obra "Depression: A Public Feeling" donde hablaba de sus experiencias vividas como persona con depresión y utilizaba unas memorias personales para teorizar y visibilizar los sentimientos encarnados de la misma. No sólo eso, sino que la autora buscaba, mediante dichas memorias, plantear otros 
métodos de investigación mediante los cuales conectar sus experiencias con las exigencias críticas de la Academia (2012: 80). Cvetkovich visibiliza, a su vez, estrategias para aprender a vivir cuando el cuerpo duele; unos dolores que le imposibilitaban, día tras día, levantarse de la cama (en un sentido tanto simbólico como literal). Siguiendo su planteamiento (Cvetkovich, 2012: 15), es importante no sólo gestionar estas experiencias de depresión y/o ansiedad, sino crear una descripción que no se reduzca exclusivamente a una lista de síntomas o que esté exenta de referirse a los sentimientos (mayormente invisibilizados) que conllevan las experiencias de ansiedad. Cvetkovich (2012: 15) reivindica, por tanto, una "escritura performativa" que tenga el poder de reivindicar lo invisible: el sentimiento de ansiedad, de tristeza, el agobio, los nervios... pero también cualquier otro tipo de experiencias encarnadas en los que la ansiedad se hace eco en el cuerpo.

Por otro lado, bell hooks (1991: 8) me enseñó a ver la escritura, y sobre todo la escritura crítica, como una intervención. Teorizar sobre el mundo que te rodea se convierte al final en una práctica combativa, en hacer sentido de aquello que (te) está ocurriendo: aquello que (te) atraviesa el cuerpo. En ese momento la escritura crítica (o “escritura performativa") se convierte en una herramienta que le otorga sentido al dolor. Y esa misma escritura puede convertirse, a su vez, en una práctica liberatoria. Con esto quiero decir que el pensamiento crítico, en el espacio en que lo enmarco, tiene como objetivo explicar el dolor para hacerlo marchar: partir de tus propios dolores para que ese ejercicio te permita dejarlos ir (hooks, 1991: 1).

Como consecuencia directa de todo lo dialogado arriba, me gustaría hacer uso no sólo de la teoría como herramienta metodológica para hablar de nuestros padecimientos, sino hablar y demostrar cómo la escritura (y, más concretamente, la escritura creativa) puede ayudarnos a repensar nuestras vulnerabilidades de forma alternativa, contribuyendo a su vez a un proceso de empoderamiento que nace en nosotras mismas y en nuestro propio cuerpo. Es un error pensar que la escritura creativa poco puede ofrecer a la investigación académica, por lo que en este trabajo me he propuesto reivindicarla como un método de investigación no sólo válido, sino urgente e importante para abordar cuestiones tan subjetivas como los sentimientos imbricados en las experiencias de ansiedad, hasta la fecha ignorados e invisibilizados.

El ejemplo más claro de lo que con este trabajo pretendo parte de las motivaciones del mismo: empiezo en mí, en mi circunstancia y me abro camino para comprender qué parte de la realidad es la que me duele y me atraviesa. No es fácil localizar nuestro dolor 
y convertirlo en un lugar para teorizar (hooks, 1991: 11), pero teorizar sobre aquello que nos produce malestar no ha de traducirse en crear un discurso vacío. Si acaso, se trata de hablar desde nuestros padecimientos, hacer de ellos la teoría partiendo de la práctica, para que podamos incluirla en nuestro día a día, y nos ayude a movernos. Cvetkovich (2012; 15) decía en su libro que en nombrar las estructuras de poder que le oprimen día tras día no encuentra el consuelo o la energía para levantarse de la cama por la mañana. Por esta misma razón me parece importante recalcar que con esta tesis de master no pretendo ofrecer una respuesta clara y concisa sobre el padecimiento de las experiencias de ansiedad, como tampoco buscar un conocimiento universalizable acerca del mismo. No obstante, me parece un buen punto de partida empezar reconociendo esas lógicas del poder estructural; darles sentido y problematizar sus dinámicas con el fin de obtener pistas y desarrollar estrategias que nos permitan (sobre)vivir diariamente.

Por esta razón, el trabajo toma como centro tres relatos de experiencias de ansiedad, unas historias que nacen del cuerpo para reivindicar lo que no se cuenta. Así, y como adelanté en la introducción, pretendo utilizar dichos relatos como estrategia metodológica para acercarme a aquello que es difícil de observar desde otras metodologías: los sentimientos, las emociones encarnadas, y, en definitiva, lo íntimo y personal. Gracias a este enfoque metodológico, la investigación alude a problemas que no se han visibilizado en la esfera pública y que no me habría sido posible puntualizar de haber utilizado otros métodos más valorados o considerados como "científicos". De esta forma, cuestiones como los sentimientos y los dolores encarnados son primordiales en este trabajo, siendo mi objetivo visibilizarlos y reivindicarlos como sentimientos ordinarios articulados en el día a día de personas que padecen ansiedad.

\subsection{NARRACión AutoetnográficA: la PERSPECTIVA DEL CUERPo.}

Escribir sobre un fenómeno que te paraliza el cuerpo requiere de formas alternativas desde las que abordar el objeto en cuestión (Visser, 2018). Desde el mismo momento en que me decanté por experiencias de ansiedad, supe que no era mi intención hacerlo desde una perspectiva positivista o cercana al canon académico. Contrariamente, mi plantemiento se centraba en hablar de sentimientos, de emociones, de crear un espacio para aquellas perspectivas que han sido invisibilizadas o ignoradas, y observar su paso a través de nuestros cuerpos, porque "lo emocional y lo personal no pueden estar separados de lo conceptual" (Gregorio Gil, 2014: 299). Mi deseo con esta investigación es realizar 
un trabajo cercano a nuestras experiencias de vida, reivindicando a su vez su relevancia dentro de las ciencias sociales, ya que, desde una visión más hegemónica, los métodos que tratan las travesías más personales han sido, a lo largo del tiempo, deslegitimados y acusados de pseudocientíficos (Gregorio Gil, 2014: 299). Por esta razón, un relato autoetnográfico, aunque no estuviese especialmente delimitado si no acompañando la investigación, me parecía una característica indispensable.

Este trabajo entiende la autoetnografía como un tipo de escritura evocativa (o en aquellas historias que se basan en la experiencia de la investigadora), de carácter personal, que relata sobre experiencias vividas y relaciona lo íntimo y subjetivo con lo político y cultural. Estos relatos evocan preguntas acerca del "yo", cuestiones que se abordan mediante escritura libre, siempre basándose en historias verdaderas que tienen como base la propia experiencia de la investigadora. Sin embargo y como adelantaba más arriba, advierto que la escritura autoetnográfica de este trabajo no se encuentra tras un apartado que indique específicamente dicha metodología, sino que mi propia experiencia aparece y desaparece a lo largo del mismo según he considerado oportuno. Por un lado, aparece porque poder reconocerse (y digo "poder" porque hacerlo es un privilegio ya que no todas las personas que padecen ansiedad se sienten cómodas o capacitadas para hacerlo) es fundamental. Por otro lado, desaparece porque la dificultad poner el "yo" me obliga, en varios momentos, a utilizar la segunda persona del singular o el impersonal; no porque no me sienta identificada, sino porque considero que el feminismo ha de resultar una herramienta con la que poder trabajar en la máxima comodidad posible, y dado que hablo de vulnerabilidades, en ciertas ocasiones he necesitado tomar distancia (Ahmed, 2017: 14).

Cogiendo como punto de partida el trabajo de Górska (2016: 197), la labor autoetnográfica dentro de este escrito se articula de forma alternativa; utilizo mi propia experiencia como herramienta para mostrar una atención y sensibilidad específicas a través de las que plantear cuestiones, intervenir y analizar, pero siempre como impulso, sin dejarme aparecer como un sujeto de estudio alternativo: en otras palabras, entiendo la escritura autoetnográfica como una aproximación que deriva de la propia experiencia de la investigadora (Allen-Collinson, 2012: 4). 


\section{CONCEPTUALIZANDO LA ANSIEDAD: UNA APROXIMACIÓN DESDE LOS ESTUDIOS DE LOS AFECTOS.}

Las dudas acerca de cómo aproximarme a mi objeto de estudio han sido muchas y muy diversas; sin embargo, tras varios meses e innumerables lecturas, encontré por fin un marco en el que la ansiedad, para mí, cobraba sentido. Recurrí a los estudios de los afectos porque entendiéndola como la corriente que "pone el énfasis en discutir la división mente-cuerpo y las dualidades asociadas", defiende que, para analizar y teorizar sobre lo social, es indispensable atender a los factores afectivos (Medina Doménech, 2012: 164). Como decía, los estudios de los afectos me han resultado, a su vez, una materia más personal, ya que es la única corriente que personalmente me ha otorgado de herramientas útiles no sólo para dialogar sobre ansiedad, sino para comprender y elaborar caminos alternativos en los que operar con ella. En definitiva, unas teorías que me hacen empezar en casa, en mi cuerpo (Cvetkovich, 2012: 4).

En este apartado trabajaré bajo la concepción de Cvetkovich (2012: 4) y utilizaré el concepto de sentimientos (en vez de utilizar el término "emociones", aunque terminológicamente me esté refiriendo a lo mismo) como categoría para aludir a los afectos, emociones y sentimientos históricamente construidos, tal vez por la comodidad de utilizar dicho término sin detenerme a cuestionar o puntualizar debates históricos dentro de este campo epistemológico. Por este motivo me referiré a los sentimientos como palabra de calle, en un sentido más genérico, en este de caso, de la forma en que sentimos las experiencias de ansiedad precisamente porque los sentimientos son "intentionally imprecise, retaining the ambiguity between feelings as embodied sensations and feelings as psychic or cognitive experiences" ${ }^{10}$ (Cvetkovich, 2012: 4). A su vez, soy consciente de que esta teorización puede resultar insuficiente, pero dado que no pretendo abrir otros caminos o discusiones que no pueda cerrar en este preciso trabajo, espero se entienda dentro del lugar teórico en que lo enmarco.

En este capítulo analizo los sentimientos o emociones como prácticas sociales y culturales, más que estados psicológicos, ya que, siguiendo a Ahmed, dichos sentimientos son relevantes para la política precisamente porque nos muestran como las operaciones

\footnotetext{
${ }^{10}$ Traducción personal: “...son intencionalmente imprecisos, retienen la ambigüedad entre los sentimientos como sensaciones encarnadas y los sentimientos como experiencias psíquicas o cognitivas”. (Cvetkovich, 2012: 4).
} 
de poder modelan nuestras corporalidades, así como la sociedad (2004: 9-12). Sin embargo, antes de comenzar me gustaría puntualizar que las definiciones y articulaciones de este marco teórico cambian activamente con aparatos discursivos de tiempos y espacios diferentes (Górska, 2016: 220). Este marco teórico particular se basa en la actualidad, una temporalidad muy particular, ya que en ningún caso sería lo mismo hablar del miedo o la ansiedad (y mucho menos al relacionarla con procesos o estructuras sociales) ahora que hace 20 años. A su vez, me interesa partir de la idea de que algunas emociones están más aceptadas en nuestra sociedad actual (siguiendo una jerarquía de las emociones o sentimientos); unas se interpretan como mejores para evolucionar mientras otras son interpretadas como una debilidad (Elias, 1978, en Ahmed, 2004: 3).

Antes de empezar, sin embargo, es necesario que aclare que este apartado está basado, con sus cambios y profundizaciones, en un texto que escribí para el libro "Disidencia en el cuerpo: Perspectivas feministas" (2019) con Ménades Editorial y como adelanto de esta tesis de máster, por lo que me serviré de la misma estructura: en el primer apartado hablaré de cómo el concepto de felicidad funciona como herramienta para favorecer las jerarquías y estereotipos sociales. En el segundo apartado, me centraré en examinar cómo las políticas del miedo (Ahmed, 2004) y el fracaso (Halberstam, 2011) son esenciales y juegan un papel crucial en cuanto a las experiencias de ansiedad, atendiendo a su vez a la relación dicotómica éxito/fracaso y su rol en la (re)producción del "sujeto ideal". Para finalizar, en un tercer apartado hablaré brevemente de cómo las biopolíticas del poder (Foucault, 1976) sirven para entender la ansiedad como una articulación del poder estructural, proponiendo a su vez otro tipo de resistencias combativas.

\subsection{El IMPERATIVO DE LA FELICIDAD: SuJETOS IDEALES Y SUJETOS DISPENSABLES.}

Una de las preguntas que habitualmente se ha hecho eco en mi cabeza en cuanto a maquetar y elaborar esta tesis de máster, ha sido referida a la presunta imposibilidad que las personas que padecen de ansiedad poseen en cuanto a alcanzar el ideal de la felicidad, entiendo la misma como el "...object of human desire, as being what we aim 
for, as being what gives purpose, meaning and order to human life" "11: la felicidad es aquello que queremos, aunque no sabemos exactamente lo que es (Ahmed, 2010: 23). Además, Ahmed lo define, más concretamente, como:

"Happiness describes not only what we are inclined toward (to achieve happiness is to acquire our form or potential) but also what we should be inclined toward (as a principle that guides moral decisions about how to live well)"12 (2010: 199).

Siguiendo el planteamiento de la autora, la felicidad no sólo haría referencia al último propósito de la vida, sino que a su vez se convertiría en una herramienta definitoria de lo que la sociedad considera como bueno, y, por tanto, como malo. Por ejemplo, cuando estoy feliz es porque estoy haciendo lo correcto o cuando todo marcha según las normas sociales, $\mathrm{y}$, sin embargo, cuando siento infelicidad, significa que algo no marcha como debería, pudiendo traducirse en que estoy haciendo algo indebido. Así, la infelicidad estaría ligada a lo que es socialmente aceptado como malo, ya que el sufrir puede leerse como un desacuerdo o ruptura con lo que ha sido señalado como bueno (2010: 210). Por lo tanto, la felicidad, además de resultar lo que buscamos, es un medidor de lo que está bien y lo que está mal según las normas socialmente establecidas. No sólo eso, sino que la felicidad queda entendida entonces como una "verdad" de toda justicia (aunque esta misma estructuración resulte injusta), que, si alguna vez es perdida, puede volver a ser encontrada si el sujeto de infelicidad se (re)direcciona de nuevo hacia el ideal citado (Ahmed, 2004: 196).

De esta forma, la autora nos introduce hacia lo que en este trabajo denominaré el "sujeto ideal", o el sujeto socialmente aceptado, que responde a los ideales sociales que toda persona debe seguir si desea alcanzar esa felicidad que es objeto de todo deseo humano. No obstante, este ideal no es un ideal fijo y puede variar según factores culturales, pero siempre define lo que entra dentro del marco estandarizado de normas sociales (por ejemplo, en occidente respondería a ser heterosexual, blanco y/o de clase media, entre otros) (Ahmed, 2004: 109). Así, las personas no necesitan ser exactamente el sujeto que cumple todos los estereotipos sociales, algo que resultaría una fantasía (o,

\footnotetext{
11 Traducción personal: “...objeto de todo deseo humano, aquello que buscamos, lo que da un propósito, significado y orden a la vida humana" (Ahmed, 2010: 23)

12 Traducción personal: "La felicidad no sólo describe hacia lo que estamos inclinadxs (alcanzar la felicidad es adquirir nuestra forma o potencial), sino que también supone hacia lo que deberíamos estar inclinadxs (como un principio que guía las decisiones morales de cómo vivir bien)” (Ahmed, 2010: 199).
} 
como explicaré más adelante, un "cruel optimismo"), sino que serían poseedores de una relación diferente hacia ese ideal o, por el contrario, el mismo ideal coincidiría con su circunstancia (heterosexual, blanco, etc.) (Ahmed, 2004: 154).

Sin embargo, sería una utopía pensar que toda corporalidad es susceptible de convertirse en un sujeto ideal, ya que no todos los cuerpos pueden habitar dichos ideales, quedando de esa forma fuera de su alcance cualquier opción de (re)direccionalidad. Un ejemplo de ello sería el caso de las personas queer, pues su mera existencia contradice las normas sociales establecidas (Halberstam, 2011: 3). Además, dentro de esta propia concepción de precariedad existe una jerarquía interna basada en las diferentes categorías existentes (sexo, género, etnia, clase, etc.) que previenen a los cuerpos de ser considerados como sujetos (Butler, 2010 en García López, 2018: 239). Esta noción es importante para entender que el mismo modelo expulsa las corporalidades consideradas "dispensables", aquellas que desde el principio no se ajustan a la norma, mediante operaciones discriminatorias como el racismo, el sexismo o la clase (entre otras). Así, el fracaso al habitar los ideales establecidos se traduce en un problema a la hora de habitar el mundo en el que vivimos, ya que falla al reproducir "el orden de la vida misma" (Ahmed, 2004: $145)$.

\title{
2.2 (RE)Dirigir A Través De Las Políticas del Miedo y DEL Fracaso: LAS OPERACIONES DEL PODER ESTRUCTURAL.
}

\begin{abstract}
"The demand for happiness is increasingly articulated as a demand to return to social ideals, as if what explains the crisis of happiness is not the failure of these ideals but our failure to follow them." ${ }^{13}$ (Ahmed, 2010: 182).
\end{abstract}

Como revela la cita de arriba, el fracaso al habitar estos ideales no se refiere al fallo de los mismos ideales, sino al fracaso de cualquier corporalidad que no sea capaz de alcanzarlos, lo que con frecuencia desemboca en un proceso de estigmatización del propio sujeto como una persona fracasada. El concepto de fracaso entendido de esta forma, está íntimamente ligado con las políticas del miedo, previamente observadas por Ahmed (2004), y las experiencias de ansiedad, de tal modo que los sistemas de poder que las

\footnotetext{
${ }^{13}$ Traducción personal: "La demanda de la felicidad está exponencialmente articulada como la demanda de volver a los ideales sociales, como si lo que explicase la crisis de la felicidad no fuese el fracaso de dichos ideales sino nuestro fracaso al tratar de cumplirlos" (Ahmed, 2010: 182).
} 
ejercen, obtienen así una forma de (re)direccionalidad hacia lo que supone el "sujeto ideal", o hacia el sujeto que interesa, que no cuestiona y reproduce las formas estandarizadas de vivir (Ahmed, 2017: 43).

Atendiendo las demandas del neoliberalismo, se fomenta no sólo la creación, sino la normalización de ese "sujeto ideal", que se adapta socialmente a las categorías aceptadas y busca reproducir una estructura social discriminatoria. De este modo, se activan mecanismos mediante los cuales el sujeto es direccionado hacia ese ideal, siendo valorado por un sistema dicotómico basado en sus éxitos y fracasos, un sistema que marca los pasos que toda persona debe seguir si desea prosperar en la sociedad en la que convive.

Siguiendo la teoría de Laurent Berlant (2011), operaría el concepto que ella entiende por "optimismo cruel". Berlant no sostiene, sin embargo, que todas las relaciones de optimismo sean crueles de por sí, sino que esta clase de relación nacería para describir el apego de una persona hacia un objeto o escena que resulta potencialmente problemática en su estructuración. Es decir, cuando el apego hacia un objeto o escena deseado despierta un sentido de posibilidad, pero cuya consecución o realización es imposible desde el principio (2011: 24). De esta forma, el sujeto en cuestión nunca cesa de buscar mejores alternativas, manteniéndose siempre activo y en órbita con las demandas neoliberales, y quedando subyugado antes las soluciones "alcanzables" pero deficientes. Siguiendo la idea de la autora, una de las razones por las que sería posible mantener tal estructura afectiva es por ese ideal fantasioso, que construye el camino por el que la gente idealiza (Berlant, 2011: 2). No obstante, el optimismo cruel no se reduce tan sólo a las esperanzas por conseguir lo ansiado, sino que la crueldad de dicha relación residiría a su vez en el miedo de perder el objeto deseado, que, siguiendo a Berlant, superaría la capacidad de tener esperanzas por conseguir nada y podría llevar al sujeto a una situación de "bloqueo" (impasse) que resultaría en la incapacidad de alcanzar dicho objetivo. Lo interesante de esta cuestión sería cómo el miedo toma forma, ya que no siempre será de consciente padecimiento, y podría traducirse simplemente en una incapacidad para manejar una situación problemática (es decir, en el miedo que nos bloquea) (2011: 24).

Tomando esta noción de miedo como crucial para entender cómo opera la ansiedad en los cuerpos con el fin de comprender sus dinámicas, me inclino a comprender el miedo como "la reacción emocional hacia una amenaza que es identificable" (Ahmed, 2004: 64-65). Además, es importante atender a estas definiciones no sólo en términos lingüísticos sino a su vez atendiendo a su temporalidad, y es que, según el planteamiento 
de Ahmed, el miedo es algo que se aproxima pero que todavía no ha llegado; algo futuro que nos afecta en el presente. Refiriéndome al concepto de ansiedad y a su relación con el miedo, Ahmed (2004: 65) establece algunas claves para entender su diferencia. Siguiendo el planteamiento en Heidegger (citado en Ahmed 2004: 66), la ansiedad se convertirá en un aproximamiento hacia los objetos, donde los pensamientos se mueven rápidamente entre ellos, pudiendo estos generar o intensificar el sentimiento de ansiedad (por ejemplo, los pensamientos intrusivos, o pensamientos desagradables que se vuelven muy difíciles de manejar) mientras que el miedo, como he explicado más arriba, es producido por el acercamiento de un objeto.

"What gets called depression in the domestic sphere is one affective register of these social problems and one that often keeps people silent, weary, and too numb to really notice the sources of their unhappiness" ${ }^{14}$ (Cvetkovich, 2012: 12).

Ante la incapacidad de llevar a cabo un modelo estandarizado de vida, el sujeto caería en un proceso de estigmatización tal, que, debido al aislamiento social ante la imposibilidad de encajar en estereotipos aceptados, más adelante desemboque en experiencias de ansiedad o depresión. De esta forma, la ansiedad podría entenderse dentro del marco teórico del optimismo cruel de Berlant (o la fantasía de conseguir un objetivo condenado al fracaso) y la noción del miedo a perder el objeto de deseo de Ahmed, incluso cuando la pérdida no haya sucedido todavía. Así, la esperanza por conseguir un objeto o escena permanece operativa, manteniéndonos alineadxs ${ }^{15}$ y en la norma, siempre en busca de otros caminos que desemboquen en una noción aceptada de éxito.

Pero, ¿qué es lo que nos produce tanto miedo? Me detengo aquí momentáneamente porque no es de extrañar que, en ocasiones, ese miedo se traduzca en no ser lo "suficientemente buena" o en el miedo de no ser capaz de cumplir lo que los ideales neoliberales nos imponen en distintos ámbitos de nuestra vida. Por ejemplo, dentro de la institución académica, un estado de ansiedad podría deberse a nunca ser o conseguir lo que se espera de la persona en relación al canon académico (sacar matrícula

\footnotetext{
14 Traducción personal: "Lo que se llama depresión en la dimensión doméstica es un registro afectivo de estos problemas sociales, y uno que habitualmente mantiene a la gente silenciada, agotada y demasiado adormecida para reconocer las causas de su propia infelicidad" (Cvetkovich, 2012: 12).

${ }^{15} \mathrm{El}$ presente trabajo incorpora de forma consciente la inclusión lingüística de los géneros haciendo uso de formas tanto normativas como no normativas.
} 
de honor o que su trabajo sea reconocido, entre otras), lo que podría influir enormemente a la hora de trabajar.

Cuando padeces ansiedad, muchas veces no es necesaria la aparición corpórea de un sistema o figura de poder que hunda tus planes o expectativas, ya que, como he explicado anteriormente, la propia norma hegemónica se encarga de crear sujetos que siempre ansíen encajar en la norma, siendo ellxs mismos la propia fuerza que se encarga de que todo salga según lo esperado. Es decir, nosotras mismas contra nosotras mismas: sabemos lo que debemos ser, los ideales se han encargado de definir por nosotras lo que está bien y lo que está mal, por lo que fracasar en la consecución de ese sujeto ideal puede traer consecuencias no sólo a nivel público, sino también en nuestra vida diaria, ejerciendo nosotras mismas la máxima represalia de semejante fracaso.

En cuanto a este respecto, Ahmed reclama:

"You might be defiant in the face of this lack of confidence. I can do that. I will be able to do that. But if those words are repeated-you can't do that; you won't be able to do that - they can become a wavering of your own will, a doubt; an uncertainty. Confidence too can shatter. A conviction "I can" transformed into a question: can I? When she is in question, she begins to question herself." (2010: 170) ${ }^{16}$

Es fácil, cuando la inseguridad se apropia del cuerpo, preguntarse a menudo si lo que haces es de verdad lo que "está bien". En momentos de incertidumbre, recurrir a un apoyo emocional parece una tarea clave, $\mathrm{y}$, sin embargo, siempre que me he decidido a contar lo que me atravesaba alguien ha alzado la voz con un discurso que centraba su base en la superación o recuperación: superar la ansiedad, los miedos que te encogen el corazón, hasta pasarlos como si tal cosa, como si "recuperar el control" hubiese estado al alcance de tu mano desde un primer momento (de este modo otorgándote la responsabilidad de cambiarlo). Cuando me refiero "recuperar el control" estoy problematizando su uso por dos razones que a continuación observaré con cuidado.

Es problemático, en un primer lugar, porque como he adelantado en el párrafo de arriba, culpabiliza a la persona con ansiedad por no haber ejecutado una solución rápida

\footnotetext{
16 Traducción personal: Puedes sonar desafiante frente a la falta de confianza. Y puedo hacerlo. Podré hacerlo. Pero si esas palabras se repiten (no puedes hacerlo, no podrás hacerlo), se convierten en una voluntad vacilante, en una duda, una incertidumbre. La confianza también puede quebrarse. Una convicción "Yo puedo" transformada en cuestión: “¿Puedo?”. Cuando ella se presenta en cuestión, ella empieza a cuestionarse" (Ahmed, 2010: 170).
} 
y efectiva desde un primer momento, una decisión que a su vez está afectando a la gente que le rodea. Cada vez que le decimos a alguien con ansiedad que "pase del tema" o que lo "supere", estamos amparándonos en nuestro propio deseo de acabar con la carga emocional que nos supone estar ahí para la otra persona. En otras palabras, el deseo de la otra persona, de la amiga, de avanzar hacia la reconciliación o superación, se debe a que la ansiedad no solo afecta a la persona que la sufre, sino también a las acompañantes de la misma (Ahmed, 2010: 216). Siguiendo este planteamiento, aquellas personas que buscan terminar con la ansiedad de otrxs mediante una alternativa tan vaga como el "supéralo", resultaría en que aquellos que padecen de ansiedad se convierten en la razón por la que otros son infelices (2010: 216). Desde esta perspectiva es interesante preguntarse por qué, entonces se tiende a entender la ansiedad encarnada como un fenómeno individual y aislado, que sólo afecta a la propia persona con ansiedad, cuando la realidad no podría estar más alejada de esta concepción.

Y segundo, "recuperar el control" es problemático porque "superar" aquello que es concebido como malo (por ejemplo, no controlar tu propio cuerpo durante un ataque de ansiedad) puede derivarnos a un proceso de reconciliación con las normas hegemónicas establecidas.

"Breathing is often understood as a tool for metabolizing panic attacks and anxieties - a method of taking control and "recovering back" into what is socially and culturally determined to be an "appropriate human subjectivity." 17 (Górska 2016: 198)

Como apunta la cita de arriba, "recuperar el control" como sinónimo de "controlar la respiración" (por ejemplo, cuando se tiene un ataque de ansiedad la respiración resulta el método que nos ayuda a volver a la "normalidad") es entendido como un proceso ambivalente y leído como un sinónimo de éxito (profesional, académico o de cualquier otro ámbito) en función a las normas establecidas socialmente. De esta forma, la noción de "recuperar el control" se convierte en un indicador que nos confirma cuándo nos hemos desviado de la norma y hacia donde debemos (re)dirigirnos. Asimismo, atender a su relación dicotómica es necesario, ya que, si bien "recuperar el control" sobre el cuerpo se entiende como una práctica positiva dentro del marco de normas sociales, "perder el

\footnotetext{
${ }^{17}$ Traducción personal: "El respirar es a menudo entendido como una herramienta para la metabolización de los ataques de pánico y de ansiedad, un método de retomar el control y "recuperarse" en lo que está social y culturalmente determinado como una "subjetividad humana adecuada" (Górska, 2016: 198).
} 
control" sobre el propio cuerpo es habitualmente leído como un proceso negativo relacionado con el fracaso. Además, los sentimientos acordados como "malos" siempre están orientados al pasado, como un problema que nos obstaculiza hacia un futuro. Y, sin embargo, los sentimientos leídos como "buenos" nos enfocarían siempre hacia el futuro, como he dicho, convirtiéndose en algo que debemos sobrepasar (Ahmed, 2010: 216).

En contraposición a este concepto de recuperación, Górska (2016) propone caminos alternativos de entender el fracaso, otorgándole a esta noción un carácter ambivalente al entenderlo también como una herramienta feminista que nos conduce a una resistencia transformadora. De esta forma, la autora rompe con la dicotomía positivista éxito/fracaso, y entiende este último como una apuesta mejor al éxito si lo entendemos como el cumplimiento de los ideales neoliberales marcados por unas normas sociales discriminatorias. Por otro lado, Jack Halberstam hablaba en su libro "The Queer Art of Failure" (2011) de cómo el fracaso está ligado estrechamente con el capitalismo, más aún, entendiéndolo como una forma de evitar (re)producir las normas del poder hegemónico, convirtiéndose así en una crítica de las mismas (2011: 88).

Aceptar el fracaso, entonces, supondría liberarse de presiones sociales establecidas, y podría conducirnos a su vez hacia otro tipo de placeres y recompensas (Halberstam, 2011: 4). Más aún, la propia fuerza de cada unx residiría en su condición de vulnerabilidad; es decir, no se trataría de eliminar la condición de vulnerabilidad sino de “construir autonomía en torno a la común vulnerabilidad” (García López, 2018: 239). Esta ambivalencia supondría también ir más allá de entender la ansiedad como un obstáculo para la vida misma, donde emprender un proceso de negociación de nuestras propias vulnerabilidades y experiencias subjetivas diarias es clave para reconfigurar esta noción de fracaso, y hacer de nuestras prácticas vitales unas "respirables".

\subsection{Biopolíticas DEL PODER Y Resistencias PeRformativas: UnA APROXIMACIÓN A LA RESPIRACIÓN DE COMBATE.}

En 1976, Michael Foucault entendía el ejercicio de la violencia de estado como parte de un sistema de poder que denominó biopoder (que, si bien no es lo mismo que la denominada soberanía, resultaría algo complementario de la misma), y que, en simples palabras, responde al poder sobre la regularización de la vida: el biopoder se centra sobre la vida porque no se puede obtener el poder de la muerte, pero sí el poder de la mortalidad. 
En otras palabras, el biopoder se centra en permitir que una vida perdure o no, por lo que su mayor herramienta es considerada la regulación de la misma. Pero el biopoder, que opera con instrumentos y tecnologías de la normalización, es el poder de regularización de la vida, es decir, de regularizar cualquier vida existente para que se adapte a las formas aceptadas de vivir (Foucault 1976, citado en Berlant, 2011: 98).

El concepto de biopoder entendido como una biopolítica sobre la regularización de la vida, me permite a su vez señalar las diferentes operaciones existentes del control, unas que pueden resultar invisibles a los ojos. Utilizar el concepto del biopoder es clave en este análisis para entender cómo la ansiedad puede ser entendida como una nueva manifestación del mismo, en la que la vida es regularizada no sólo por medio de guerras o colonizaciones, sino mediante un sistema capitalista y neoliberal que nos arrebata nuestro valor, nos hace sentir inútiles y pequeñas y sin esperanza alguna de un futuro mejor (Cvetkovich, 2012: 13). Otro ejemplo de ello sería lo que Berlant (2011) denomina como la "muerte lenta", en la que atiende al problema de la obesidad proponiendo así otra forma de operación del poder capitalista sobre las vidas colectivas, una que ofrece una solución gratificante que a largo plazo está causándoles la muerte (esta, a su vez, resultaría otra encarnación del optimismo cruel).

Por otro lado, y hablando particularmente en el contexto de las enfermedades mentales, se ha demostrado que, desde la psicología, se han patologizado diversos aspectos que tienen más que ver con la expresión de las incapacidades o críticas de las mujeres (es decir, con su reacción a la violencia institucional) a "a los roles prescritos a través de la construcción social de la diferencia sexual; es decir, protestas conscientes o inconscientes contra su «colonización»" (Cabruja i Ubach, 2007: 159), de esta forma señalando las consecuencias de desviarse de las normas hegemónicas existentes. En otras palabras, las disciplinas psicológicas y psiquiátricas son usadas como métodos para conseguir el control de las subjetividades, y por ende, el control social (Foucault, 1966 citado en San Martín, 2007: 172-173).

Esta forma de entender el poder, resuena a su vez en lo que el filósofo martiniqués Frantz Fanon entendía como "respiración de combate" en su crítica contra la violencia de estado producida por la colonización francesa sobre Algeria (y, más particularmente, sobre lo que dicha colonización supuso para el cuerpo de las mujeres, que se armaron con el velo como respuesta directa a las operaciones del poder estructural). 
"There is not occupation of territory, on the one hand, and independence of persons on the other. It is the country as a whole, its history, its daily pulsation that are contested, disfigured, in the hope of a final destruction. Under these conditions, the individual's breathing is an observed, an occupied breathing. It is a combat breathing" (Fanon, 1967: 50). ${ }^{18}$

Siguiendo a Fanon (1967), los intentos de resistencia de la ciudadanía resultaron en el mero hecho de respirar contra la ocupación; es decir, el sujeto político subyugado a semejante acto de violencia es despojado de cualquier estatus y reducido a un estado de respiración de combate, donde el respirar se convierte en el mayor intento de supervivencia del pueblo. Así, la "respiración de combate" nombra la movilización de sujeto por el mero hecho de respirar y sobrevivir el ejercicio de violencia del Estado (Perera \& Pugliese, 2011: 1). Para Fanon, el sujeto marcado como objetivo por las estructuras de poder se reduce a la figura de un cuerpo desechable:

“(...) to a soma of such utter political and economic vulnerability that the very possibility of respiration becomes the ultimate challenge. As such, the target subject's energies are fully committed merely to surviving; as such, the logic of state violence is predicated on ensuring that the subject cannot begin to expand their energies in resisting, contesting or subverting the power of the state" (Perera \& Pugliese, 2011: 2). ${ }^{19}$

Sin embargo, la "respiración de combate" no siempre se ha articulado para criticar las operaciones de poder de las necropoliticas (MBembé, 2003), ya que originariamente respondía a la táctica militar utilizada para pasar o moverse en una situación de bloqueo. El ejercicio consistía en una serie de respiraciones controladas que ayudasen al sujeto a continuar, y que, lejos de "recuperar" el estado de tranquilidad en la persona, buscaban el movimiento automático para superar una situación de peligro inminente (Perera \& Pugliese, 2011: 11).

\footnotetext{
${ }^{18}$ Traducción personal: "No hay ocupación del territorio, por un lado, e independencia de las personas, por otro. Es todo el país en su conjunto, su historia, su pulsación diaria los que son contestados, desfigurados, en la esperanza de una destrucción final. Bajo estas condiciones, la respiración individual es una respiración observada y ocupada. Es una respiración de combate"

${ }^{19}$ Traducción personal: "a un cuerpo de una vulnerabilidad económica y política abrumadora que la misma respiración se deviene en su último reto. Como tal, las energías del sujeto marcado se hallan completamente entregadas a su supervivencia; así, la lógica de la violencia del estado se mantiene siempre y cuando el sujeto no pueda comenzar a expandir sus energías en resistir, contestar o subvertir el poder estatal" (Perera \& Pugliese, 2011: 2).
} 
En este sentido, el concepto de "respiración de combate" está tanto simbólica como originariamente ligada al concepto del dolor encarnado, donde la relación entre respiración y ansiedad radica en que esta última constituye una de las representaciones particulares de la respiración (Górska, 2016: 204).

En este trabajo, entiendo la "respiración de combate" como una resistencia alternativa y encarnada frente a la hegemonía de las estructuras y operaciones del poder ante el malestar y el miedo que produce ser catalogadxs como un fracaso. Estos malestares que no puedo pasar por alto, son a su vez visibilizados en nuestros cuerpos en forma de dolores o padecimientos. Al hablar de dolor, me referiré particularmente al entendimiento de Das (2008), refiriéndose al mismo como el modo en el que el daño histórico hacia una persona puede ser representado. A veces en forma de síntomas individuales, y, otras veces, como una memoria inscrita en el cuerpo. Entendiendo el dolor de esta manera, no puedo sino referirme a la importancia del cuerpo como una materia social previamente constituida. En otras palabras, el cuerpo no puede ser entendido simplemente como una materia natural, ya que "está atravesado por normas, dispositivos y mecanismos sociales" (García López, 2018: 238). Al hablar del cuerpo, por tanto, hago también referencia a su dimensión pública, social y cultural, y de cómo la violencia ejercida por los sistemas de poder elige y discrimina qué cuerpos son importantes y qué cuerpos son "dispensables”.

"The daily muscle tensions, pressures, suffocation, the circular thoughts and fears, and the pain in the jaw are anxious performative materializations of corpo-affective agential struggle with social power relations and a demand for reconceptualization of the dominant notions of human subjectivity and transformation of social, political, economic, cultural and ecological power relations" (Górska, 2016: 278). ${ }^{20}$

Como revela la cita de arriba, estos dolores son importantes para reconocer(nos) en nuestros propios cuerpos, pero también en cómo estas manifestaciones nos hablan de las luchas diarias y las continuas negociaciones a las que nos vemos sometidxs para conciliar una vida "válida", subjetiva y fuera de las normas hegemónicas. En otras palabras, es imposible entender la ansiedad exclusivamente mediante teorías; la ansiedad

\footnotetext{
${ }^{20}$ Traducción personal: "Las tensiones musculares diarias, presiones, asfixia, ideas y miedos circulares, y el dolor en la mandíbula son ansiosas materializaciones performativas de una lucha agencial cuerpo-afectiva con las relaciones sociales de poder y una demanda por la reconceptualización de las nociones dominantes de subjetividad humana y transformación social, política, económica, cultural y relaciones de poder ecológicas” $(2016,278)$.
} 
comienza y se manifiesta a través del cuerpo. Y ciertamente, no podría hablar de experiencias de ansiedad sin hacer referencia, entre otras, a la sofocante presión en el pecho, la fuerza de una mandíbula apretada hasta la extenuación, o los incansables viajes a través del pasillo de casa, tan sólo para liberar las tensiones que nos habitan y debilitan el cuerpo. La perspectiva corporal esconde una narrativa política crucial, ya que muchas veces estas críticas a las estructuras de poder no pueden expresarse verbalmente, acogiéndose literalmente a nuestros cuerpos. De esta forma, "el lenguaje del cuerpo se convierte en crítica cuando el individuo se enfrenta con acontecimientos que se sitúan fuera del curso de la experiencia normal" (Das, 2008: 412). No es posible la concepción de una teoría sin práctica, como tampoco lo es hablar de ansiedad sin mencionar la experiencia física y corporal de la misma, aquella que, como he mencionado más arriba, performa registros de resistencia frente a las normas hegemónicas establecidas. Entre muchas otras experiencias, estas manifestaciones conforman las articulaciones de la ansiedad sobre el cuerpo, y variarán según la persona y el contexto social, político y económico de la misma, por lo que no busco hacer de estas experiencias un saber universal, como adelantaba en el primer capítulo.

Cómo hacerles frente a las operaciones del poder estructural es y continuará siendo una lucha exhaustiva, que requiere de nuestra fuerza constante y diaria: entrar en procesos de negociación de nuestras propias vulnerabilidades, y revalorizar aquello que nos categorizaron como negativo, pues es en nuestra propia vulnerabilidad donde encontramos y performamos actos de resistencia, ya que en ellas mismas se encuentra el cambio transformativo (García López, 2018: 239). De esta forma, la vulnerabilidad adquiere otro sentido al reconocerla, ya que de esa forma nos permite, a su vez, reconstituirla. Es decir, una vez la vulnerabilidad de una misma es reconocida, se abren nuevos caminos para repensar la estructura de la misma (Butler, 2006: 70-71).

La idea partiría de cuerpos que se juntan y de cuerpos que prosperan individualmente, pero se construyen en relación a otras corporalidades: cuerpos que "respirando juntos, se unen vulnerablemente en la necesidad de condiciones materiales para la vida" (García López, 2018: 241-242). 


\section{RELATOS DESDE LA SUbALTERNIDAD: LA ANSIEDAD COMO RESISTENCIA DE COMBATE.}

El presente capítulo se estructura en tres apartados; el primero de ellas recoge algunos de los interrogantes y las luchas actuales referentes a las experiencias de ansiedad, con el fin de situar en contexto dichas prácticas combativas. Así, para entender el marco socio-político en el que estas experiencias se enmarcan, elaboro en primera instancia un apartado que nos sitúe en el ahora, en el espacio en que se han desarrollado y que suponen una contrariedad a lo que Górska (2016) denomina como una "subjetividad humana adecuada".

En segundo lugar, me detengo sobre la dimensión de género que atraviesa un fenómeno como la ansiedad. Atender particularmente esta categoría me ayudará a explicar por qué las tres personas que he decidido incluir en la investigación, se sienten identificadas con la categoría "mujer”. Además, y como explicaré en dicho apartado, al atender dicha categoría, surgen nuevas variables a tener en cuenta en el trabajo para el análisis.

Por último, al final de este capítulo pueden encontrarse los relatos, tres piezas que narran el día a día de tres experiencias subjetivas de ansiedad.

\subsection{ConteXto Socio-Político: Estigmatización $\quad \mathrm{Y}$}

LENGUAJE.

Aparte de la estrecha relación con las mujeres que han dado vida a este trabajo, existe otra razón por la que puedo decir que me topé con la ansiedad de cara, sin pensarlo ni esperarlo, quizás hasta tal punto que podría pensar que es el tema quién me escogió a mí y no al revés. Ese día yo estaba sentada en mi ordenador, y como tantas otras veces me metí en las redes sociales para enterarme de lo que estaba ocurriendo fuera de casa, ya que por aquel entonces vivía en un país extranjero. Me percaté de que hacía tiempo que revisar las redes se había convertido en un ejercicio rutinario que más que distraerme me provocaba malestar, y no fui consciente de la razón hasta que, como expliqué en la introducción, mis compañeras empezaron a nombrar sus experiencias, poniendo fin a la 
invisibilización y tabú que se cierne sobre ellas: me di cuenta de que no hacía más que ver esas experiencias día tras día. Eran personas que conocía, pero también completas desconocidas. No sabía desde cuándo, pero las redes que frecuentaba se habían convertido en un lugar de compartir y desahogar, de denunciar comportamientos abusivos y operaciones de poder.

Esta cuestión es importante y me gustaría detenerme brevemente sobre ella. Como he destacado en el párrafo de arriba, no fue hasta que mis compañeras comenzaron a hablar de ansiedad que yo supe reconocer, más adelante, diversos episodios que estaban teniendo lugar en mi cuerpo. La dificultad del (auto)reconocimiento es un problema que sigue vigente en nuestra sociedad, y este trabajo me centro en dos razones particulares a la hora de abordarlo lingüística y políticamente. De un lado, me gustaría destacar que es fácil olvidarse (o no ser consciente) de algo que no se siente o padece: los pensamientos o experiencias de las que estoy protegida son aquellas en las que no tengo que pensar (Ahmed, 2017: 181). Aquí entra en cuestión el privilegio del cuerpo "capacitado", el cuerpo que al no padecer de x dolores o padecimientos, no entiende y no piensa acerca de ellos. Este privilegio que no entendemos desde una perspectiva corporalmente privilegiada constituye un factor que invisibiliza: yo no fui consciente de lo que era la ansiedad hasta que la ansiedad me golpeó cada musculo del cuerpo, y fue entonces cuando reconocí su existencia.

Por otro lado, y como segundo factor que juega un papel muy importante en el (auto)reconocimiento de las experiencias de ansiedad, está el lenguaje. Por ejemplo, cuando se evita usar el término "ansiedad" al describir sus lógicas y dinámicas; al evitar darle nombre, o al suavizar el problema en cuestión, estamos eliminando los recuerdos del dolor y reproduciendo las dinámicas de invisibilización que avalan las normas hegemónicas de una subjetividad adecuada y aceptada (Ahmed, 2017: 184). En su libro, Ahmed (2017: 102) utiliza el símil de la sonrisa para explicar estas operaciones: la sonrisa que aparenta de cara al público simular tranquilidad y normalidad, cuando en realidad nada de eso puede leerse bajo la atenta mirada de las operaciones hegemónicas. No obstante, si la sonrisa no se produce se crea un estado de incomodidad en el entorno, ya que se está visibilizando un problema y creando malestar a aquellas personas a las que la norma les sienta cómoda. Estos mecanismos se activan para evitarles un problema al resto, ya que, de alguna forma, esa "infelicidad" puede empatizarse. Si tú admites que hay un problema, yo tengo que admitir que hay un problema, creando un problema hacia mí misma. 
Es a través de estas dinámicas que aparece el estigma (“está triste y no hace nada para enmendarlo"), que podemos definir como:

“...el efecto negativo que una marca o una etiqueta produce en un grupo, tal como una minoría étnica, religiosa o pacientes con ciertas enfermedades entre las que se destacan el sida y la enfermedad mental. El estigma incluye tres elementos: un problema de conocimiento (ignorancia), un problema de actitud (prejuicio) y una conducta (discriminación)"(Uribe Restrepo, Mora, \& Cortés Rodríguez, 2007: 208).

Los prejuicios mencionados arriba serían una de las causas principales de una situación de discriminación o injusticia política (Uribe Restrepo, Mora, \& Cortés Rodríguez, 2007), suponiendo a su vez una de las causas principales por las que muchas de las personas que padecen ansiedad no buscan tratamiento en un primer lugar (Anderson, Jeon, Blenner, Wiener, \& Hope, 2015: 131). Los estigmas que se refieren a las enfermedades mentales pueden tener diferentes efectos a día de hoy, particularmente cuando se habla de ansiedad, donde, según un estudio (Anderson, Jeon, Blenner, Wiener, \& Hope, 2015), se tiende a separar al sujeto estigmatizado mediante una pérdida de estatus, discriminación y diferencias en el poder político, económico y social.

El hecho de nombrar una enfermedad mental puede suponer una carga social (y política y económica) negativa para el colectivo estigmatizado. Por ejemplo, cuando me aproximé a las mujeres que más tarde me prestarían sus relatos, yo misma traté de evitar palabras como "trastorno mental" o "enfermedad mental" presuponiendo que utilizar ciertas denominaciones podrían molestar o incomodar a personas tan cercanas. Siguiendo el artículo de Katie Aubrecht (2012), que formula desde los disability studies, las Naciones Unidas han denunciado que la discapacidad (término que incluye las enfermedades mentales) es una "crisis silenciosa" mundial, ya que nuestras respectivas lenguas maternas no nos han otorgado a un mayor conocimiento acerca de las mismas con el objetivo de reducir los niveles de discriminación.

Más aún, como protesta política, Aubrecht (2012: 34) reclama: 
"In identifying as a disabled person and not as a person with a disability, I seek to "transgress" the normative demand to remove and distance myself from disability through use of the word "with." 21

El debate en cuanto a revalorizar identificarse como una persona discapacitada o con una enfermedad mental es diverso, y aunque no pretendo indagar o rebuscar en él, si creo conveniente señalar que es irresponsable pensar que dichos apelativos juegan un papel inocente; es decir, que nada tienen que ver con la jerarquía, o las categorizaciones y estigmatizaciones sociales. Importa cómo hablamos del mundo, porque al hacerlo estamos materializándolo y trayéndolo a la existencia (Ahmed, 2017: 230). Particularmente, el lenguaje referido a las enfermedades mentales se rige bajo la normatividad del lenguaje y el conocimiento psiquiátrico, que nos instruye en ver la discapacidad o enfermedad mental como una desventaja individual que ha de ser "arreglada" para adaptarse a lo que la cultura occidental entiende como "vida sana" (Foucault, 2003 en Aubrecht, 2012: 37). Es necesario entender la importancia de abordar una noción como la discapacidad de forma política, y por tanto de leer dichas categorías de formas alternativas y performativas (Titchkosky, 2007 en Aubrecht, 2012: 34).

El lenguaje no es estático, cambia acorde a las relaciones y organizaciones sociales vivenciales, cambia en el tiempo y cambia en el contexto. Tal vez sea momento de revalorizar y reivindicar, de sentirse cómodas y reconocerse dentro de los colectivos con el fin de hacer visibles las luchas colectivas que tanto tienen que ver con crear vínculos sororos. A las experiencias de ansiedad, así como cualquier otro tipo de enfermedad mental no las une una misma experiencia, ya que todas son diversas y diferentes entre sí. No obstante, existe una responsabilidad colectiva y un deseo y necesidad de vivir, de forma digna, la vida misma (Aubrecht, 2012: 41).

\subsection{NO ESTAMOS LOCAS, ESTAMOS HARTAS: LAZOS SOROROS Y DIMENSIÓN DE GÉNERO.}

Para explicar el vínculo compartido entre las mujeres que dan vida a este trabajo y yo misma, me gustaría recuperar una vivencia narrada en el capítulo uno: mi experiencia

\footnotetext{
${ }^{21}$ Traducción personal: "En identificarme como persona discapacitada y no como persona con discapacidad, busco "transgredir" (p.137) la demanda normativa de erradicar y distanciarme de la discapacidad a través del uso de la palabra "con" (Aubrecht, 2012).
} 
en los foros de literatura juvenil, y particularmente cómo dicha plataforma me sacó de la burbuja tan difícil en la que me encontraba en la adolescencia. Retomo esta experiencia porque hasta ahora no he mencionado que las personas que hoy escriben sus relatos en este trabajo supusieron para mí un gran apoyo durante esa época; más aún, ellas me acompañaron en el proceso creativo, pues también eran usuarias de dichos foros de literatura. Así, este ejercicio de escritura nos hace comenzar en casa, ya que durante años escribimos juntas (no necesariamente sobre el tema que aquí nos atañe), crecimos juntas y nos apoyamos mutuamente. El hecho de habernos escrito y leído durante un periodo tan largo de tiempo (desde la adolescencia hasta la actualidad) construye lo íntimo de esta investigación, ya que como digo, no se trata de un hecho aislado sino de una experiencia de vida. Además, al haber compartido durante varios años este gusto por la escritura colectiva, surge un lazo de confianza, cuidados, respeto y sororidad, que no habría podido plasmarse de haber traído aquí tres relatos cualesquiera. En nuestros personajes se plasmaban nuestras incertidumbres, nuestras dudas y nuestros anhelos, los de la época y los que surgieron más adelante, y hoy en día la escritura sigue resultando un ejercicio de unión. Este factor, el de la escritura colectiva de mujeres, supone, entonces, un elemento indispensable en la elaboración de este trabajo, pues hace referencia al vínculo que compartimos.

No obstante, existe otro factor fundamental a tener en cuenta en cuanto a la elección de contar con mujeres en este trabajo: escogí contar exclusivamente con mujeres porque parece innegable que la salud mental y el género han devenido históricamente de la mano. Particularmente, un gran número de estudios sobre salud y género nos indican que actualmente existe un mayor porcentaje de mujeres con problemas de salud mental (Cabruja i Ubach, 2007: 159). Acorde a la necesidad de reivindicar esta relación, el movimiento feminista ya se ha encargado de abordar el tema en diversas ocasiones. Un ejemplo que resuena estruendosamente en la agenda feminista se remonta a 1963, cuando Betty Friedan conceptualizaba, desde un feminismo liberal, "el problema que no tiene nombre" para referirse al malestar que sentían las mujeres americanas en los sesenta, en un texto social, político y económico muy particular.

No obstante, al decir que los problemas de salud mental han estado históricamente relacionados con la vida de las mujeres, no pretendo invisibilizar otras realidades de colectivos vulnerables que también son objeto habitual de este tipo de experiencias; más aún si las pensamos desde un marco de discriminación social, política y económica en relación a todo lo expuesto en el capítulo dos, pero, dada la escasez de tiempo y espacio, 
sólo me centraré en la categoría "mujeres", y más particularmente, en la experiencia de tres mujeres jóvenes, blancas y de clase media.

Para explicar brevemente la relación existente entre salud mental y mujeres, me parece interesante aludir a un concepto particular muy ligado a las enfermedades mentales: el concepto de "locura" que históricamente se nos ha atribuido a las mujeres. Esta noción aparece aludiendo a una subjetividad alternativa, ya que todo lo que no se ajusta a la norma hegemónica o a la experiencia vivencial de una subjetividad adecuada, queda categorizado como un enloquecimiento (Cabruja i Ubach, 2007: 169). Así, la patologización de la locura surge con el incumplimiento o la ruptura de la feminidad en una sociedad patriarcal, levantada sobre los cimientos de las desigualdades de género (Cabruja i Ubach, 2007: 165). Estar "loca" es estar enfadada, se articula como una crítica hacia el discurso hegemónico; cómo al no ser capaces de vivir bajo esa jerarquía (social y emocional) hemos de estar "rotas", o, más ordinariamente, "locas". Como consecuencia, esta categorización supone uno de los mecanismos que mencionaba en el capítulo dos, un dispositivo que tiene objetivo (re)direccionarnos hacia la norma.

De esta forma retomo la idea de rehabitar los fracasos, y en este caso particular, la locura, para entenderla como una herramienta de combate feminista. Al habitar esta noción de forma alternativa, estamos evitando reproducir las normas hegemónicas, y abriéndonos camino hacia una nueva forma de vivir nuestras en nuestros cuerpos vulnerables.

\subsection{RELATOS DE ANSIEDAD: NUEVAS ALTERNATIVAS DE RESISTENCIAS COMBATIVAS.}

En el siguiente apartado pretendo acercarme a la ansiedad de hoy a través de los relatos de escritura creativa realizados por tres mujeres de mi entorno. Como he explicado anteriormente, el objetivo principal es ofrecer un espacio donde estas experiencias tengan cabida y puedan ser visibilizadas, sin ningún tipo de juicio y entendiendo que no tienen por qué relatar experiencias parecidas. La decisión de colocar los relatos en el cuerpo de la investigación y no en anexos se debe a hacerle justicia a uno de los objetivos, el que, como decía más arriba, indica esta investigación como un espacio para compartir experiencias, precisamente porque son lo central de mi exploración y merecen estar dentro de la misma. 
Los relatos llegan a este trabajo tras varias conversaciones y tres llamadas de teléfono, pues desde el momento en que compartí el proyecto, mis compañeras se mostraron motivadas. Cómo llegaron a esos relatos es algo que a continuación expresaré brevemente, basándome en el propio discurso de las autoras, el que compartieron conmigo antes de mandarme sus piezas. Además, también expresaré algunas características que considero importantes para entender la procedencia, contenido y forma de los escritos.

El relato de Eva no se escribió específicamente para el trabajo, sino que es resultado de un ejercicio de cuidados y sanación que más tarde decidió compartir conmigo: la autora buscaba, mediante la escritura de sus emociones encarnadas, dejar ir el dolor, seguir hacia delante tras un acontecimiento que potenció sus malestares. Escribir todo el proceso supuso para ella una forma de afrontar sus sentimientos y abrazar sus emociones.

El relato de María es una combinación de intereses: de un lado, escribir sus malestares fue una demanda expresa de su psicólogo, también como forma de gestionar las emociones y la ansiedad, o una forma de aliviar sus tensiones corporales. De otro lado, su relato en particular fue pensando desde un primer momento para esta investigación, eligiendo compartir una experiencia vivencial de tiempo atrás.

Por último, el relato de Marina compone uno de tantos que guarda en su cuaderno de reflexiones, donde deja fluir los sentimientos que no se siente capaz de expresar en voz alta. Hace años que la escritura se convirtió en su vía de escape, y desde entonces le gusta regalar cuadernos en blanco, por si alguna de nosotras necesitamos de un espacio propio donde conversar con nosotras mismas. 


\section{RELATO I: CICATRICES VIII}

\section{Sobre la autora:}

Eva es un $40 \%$ música. Siempre está sonando en su cabeza o en sus auriculares. Un $20 \%$ es todo baile, teatro y focos. Zapatillas de ballet, tirones y coreografías eternas. El $40 \%$ restante es indescifrable: hay letras, historias, poemas y heridas; hay sentimientos que se entierran, pero nunca desaparecen; hay noches sin dormir y pesadillas; hay cientos de elementos en apariencia inconexos pero sin los que Eva no podría ser, ni sería, quien es. $^{22}$

${ }^{22}$ Presentación realizada por la propia autora. 
Todo lo que se alzaba a su alrededor se hizo cenizas y volvió a aparecer en su habitación. Su habitación extrañamente pequeña. Había intentado mover los dedos y se había encontrado, de nuevo, paralizada, hechizada por los chillidos burlones $\mathrm{y}$ movida como un títere por esa presencia que, otra vez, volvía a sentarse sobre su mejilla, hundiéndole el rostro en la almohada.

En el escaso tiempo que duró la siesta, Boom Baby llegó a querer desmayarse de verdad alrededor de cinco veces.

Para cuando sacó valor para mover los músculos y cazar su teléfono, el azar ya se había sumado a la fiesta de joderle la vida. De joderle la tarde. De joderle lo poquito que había construido en las últimas dos semanas.

Aún con el mal cuerpo de esas visitas non gratas y de esos besos que se habían quedado pegados a su boca, se encontró un mensaje justamente tuyo. Y ya, ahí, ella sabía que el chiste no le iba a hacer gracia. Por eso torció ligeramente el gesto mientras se preguntaba por qué la tratabas así, y por eso, demostrando que aún eras su talón de Aquiles, tecleó una pregunta nimia. Un sencillo “¿estás bien?”.

Pero la pobre Boom Baby, en lugar de una respuesta agradable, recibió un corte limpio. Un puñetazo de esos que cortan la respiración. Y como contigo peca de tonta, insistió, porque las hostias no eran pocas si se las dabas tú.

$\mathrm{Y}$, por dios, no te imaginas cómo resonó por las paredes el revés que le diste.

El móvil cayó de nuevo sobre la cama $\mathrm{y}$, cuando rodó hasta quedar boca arriba, la magia sucedió.

El escozor de este último golpe se transformó en la gota que lo colmó todo y la habitación se empequeñeció dejándola a ella dentro.

El estrés que llevaba acumulando días, o incluso meses, le corrió por las venas como si fuera pólvora y la parálisis le alcanzó los pulmones. Sus ojos recorrieron las paredes como quien nunca antes las había visto y estas, como respuesta, se estrecharon y estrecharon y estrecharon, como si buscasen consolarla, abrazarla.

¿No estabas triste, BB?

Clavó las manos en el colchón para incorporarse y, solo cuando su espalda dio con una de las paredes, fue capaz de sentir en toda su gloria el efecto de todos los golpes. Notó el pecho cerrado, como si le hubieran puesto un candado, y las garras que antes le aplastaban la mejilla ahora hacían presión allá donde se formaba la unión entre corazón y pulmones.

La temperatura del agobio llegó a su punto álgido $\mathrm{y}$, abriendo la ventana como si pesara toneladas y quitándose la chaqueta, se 
preguntó si la broma no había sido ya suficiente. Porque no tenía gracia.

Hacía semanas que había dejado de ser divertido hacerla llorar.

Pero, sin querer, tú lo habías vuelto a hacer.

$\mathrm{Y}$ aunque la pesadilla esta vez fuera tangible y real, aunque la angustia no saliera de su cuerpo hasta pasados varios minutos, ella ese día tampoco consiguió odiarte. 


\section{RELATO 2. TERRORES NOCTURNOS.}

\section{Sobre la autora:}

A María le encanta la pizza. Y los sábados. Pero le gusta mucho más cuando ambas cosas van de la mano. También ama a su perro, que siempre parece estar dispuesto a echar la pata que haga falta, incluso cuando se queda sin aire. Su tiempo libre lo pasa batallando, aunque sea digitalmente. Le encanta viajar y se recorrería el mundo siguiendo a sus artistas favoritos. ${ }^{23}$

${ }^{23}$ Presentación de la autora realizada por mí. 
La última noche que pasó, pensaba que estaba a punto de morir. Llevaba varios días sin dormir, empalmando trabajo con responsabilidades, con actos sociales, con meterme en una cama que sentía una condena y, al final, exploté.

Supongo que debería de haberlo visto venir cuando mi perro empezó a demandar más mi atención y me empezó a seguir por toda la casa como si fuese a desaparecer de un momento a otro. Daba igual la hora: Dante siempre estaba pisándome los talones a las dos de la madrugada o a las once de la noche, mientras yo deambulaba por la casa con un vaso de leche caliente en la mano y los ojos rojos de cansancio. A veces, me acurrucaba en el sofá y él saltaba a mis brazos, y entonces yo empezaba a llorar de desesperación y de dolor y él me lamía, pensando que eso haría que me encontrase mejor. En cierto modo, lo hacía - y lo sigue haciendo: cada vez que le miro me siento un poquito mejor-, pero los dos sabíamos que ahí no acababa mi aventura.

Y eventualmente volvía a la cama. Y eventualmente me volvía a levantar. Así, una y otra, y otra noche.

Seis horas, cinco horas, cuatro horas, tres horas... Miraba el reloj como si me estuviera engañando, como si alguien tratase de robarme los minutos de descanso. Al principio, no entendía nada; después, até cabos.
Irónicamente, a pesar de no dormir absolutamente nada durante varios días - $-\mathrm{y}$ pensar que iba a colapsar de un momento a otro-, mientras el sol estaba en el cielo me encontraba activa. Podía hacer todo lo que me pidiesen en la oficina y más, me tomaba un café para acompañar el malestar corporal y volvía al ruedo. Me iba a pasear a medio día. Hacía una vida completamente normal, incluso me cundía el tiempo más que hacía unos meses. Quizá porque las jornadas, para mí, tenían más horas.

Procuraba tener todo hecho para medianoche, entonces comenzaba todo. Puede que se me estuvieran cerrando conforme avanzaba el día, pero tenía clarísimo que en cuanto mi cabeza rozase la almohada no iba a conseguir descansar. A veces sí, a veces caía como un tronco al segundo y me despertaba en medio de la noche como si alguien me hubiese dado un susto; otras, simplemente, mi cerebro no desconectaba. Y la razón era tan sencilla como aterradora: me daba miedo. Mi cuerpo empezaba a hundirme en el colchón, con un dolor de pecho que pensaba que iba a romperme las costillas, y después me estrangulaba sin que yo pudiese coger aire. Solo mirar hacia arriba, hacia ese techo que se venía abajo y del cual no podía escapar, porque si me levantaba y caminaba un poco, mis piernas respondían por pura inercia, y si cogía algo para distraerme y que el cerebro pensase en otra cosa, me echaba a llorar porque sabía que no iba a poder dormir. 
Era un círculo vicioso que llevaba a que a veces tuviera visiones durante el día, o a que cualquier roce me provocase de nuevo esa sensación de ahogo que, creía, era para siempre.

Hay una cosa que siempre consigue tranquilizarme, y no es que mi madre me acune como a un bebé, o que alguien me diga la obviedad de que todo es pasajero. Mi perro duerme en una cama de litera que reclamó en el mismo instante en que puso una pata en casa por primera vez, y siempre está ahí cuando le necesito. Incluso medio dormido, incluso queriendo descansar él, me ve aparecer por la puerta y me hace un gesto para que me acerque y le abrace. Entonces, escucho su corazón a través de la piel y el mío se acompasa a su tranquilo movimiento. A veces, gira la cara para darme un beso en la mejilla y acomoda su figura larga y gorda a la mía.

Supongo que los animales saben leer las emociones humanas mejor que nosotros mismos, porque la noche en que exploté, la última noche en que vi el irme a la cama como una tortura y no como un merecido premio, Dante empujó varias veces la puerta de mi habitación, pidiendo entrar. Yo le abrí, con las mejillas mojadas de las lágrimas de desesperación y una mano en el pecho, tratando de convencer a mi cuerpo de que dejase espacio para respirar. No dijo nada, ni hizo ningún ademán de mirarme desde su posición: se subió al colchón, palmeó a su lado — esto es algo que hace mucho; pensamos que puede ser un humano en el cuerpo de un animal- y yo le hice caso.

No pegué ojo en toda la noche. Ni siquiera un minuto. Mi perro tampoco lo hizo y, cuando mi padre empezó a buscarle para sacarle a pasear, se bajó perezoso de la cama y me miró una última vez, como advirtiéndome de que debía buscar ayuda.

Aquella misma mañana fui corriendo al médico para que me ayudase. Cuando volví a casa, por la tarde, y me vio con unas bolsas con pastillas, me sonrió y volvió a palmear el sofá, a su lado, para darme un beso.

La cama ha dejado de ser un lugar terrorífico, pero sigo ahogándome muy a menudo. Por suerte, siempre tendré otro corazón que late más despacio que el mío y un peluche paciente al que nunca le importe ayudarme a sobrellevarlo cada día un poco mejor. 


\section{RELATO 3.}

\section{Sobre la autora:}

Me llamo Marina y tengo 20 años. Hoy me han dicho que me define la expresión 'amarilla por dentro pero azul por fuera'. Luego, me han explicado que significa que soy increíblemente alegre pero mi fachada es azul, porque estoy más tiempo triste del que debería. Cuando no pienso en todo lo que me rodea soy la persona más feliz del mundo. Si me paro a pensarlo, dejo de serlo. Así que, actualmente, estoy intentando dejar de pensar. Funciona.

También me gusta ir de acampada y mi cosa favorita en el mundo es ver las estrellas de noche. Y los árboles. ${ }^{24}$

${ }^{24}$ Presentación realizada por la propia autora. 
Cada vez que he intentado escribir sobre ella nunca he sido capaz porque siempre me faltan las palabras. Ni tan siquiera puedo describirla. Es algo muy complicado porque ella es muy complicada.

Está conmigo siempre y ni siquiera sé cuál es su rostro. Tampoco sé dónde está, ¿en mi mente? ¿En mi pecho? ¿En mi garganta? La he sentido en todos y cada uno de los sitios. No sé nada sobre ella y, hasta hace un par de meses, ni tan siquiera sabía cómo se llamaba. Incluso llegué a dudar si existía o si simplemente me estaba volviendo loca. Me acompaña en mis momentos de mayor tristeza y, desde hace tiempo, también lo hace en los momentos de mayor felicidad. Por mucho que no lo quiera, nunca me deja sola. Y aún así, nunca se la presentado a nadie porque no quiero que sepan que me acompaña en todo momento. Me da vergüenza reconocer que siempre vamos de la mano.

Supe cuál era su nombre un día que me encontró en medio de una clase en la universidad y, desde entonces, no puedo pisar aquel edificio. Me pilló por sorpresa cuando pensaba que lo tenía todo controlado $\mathrm{y}$, desde entonces, no he tenido bajo control nada. Perdí las riendas de mi vida el día que supe que, gracias a ella, nunca más podría controlar nada. Porque ella es así: inestable, inesperada. Es el desorden hecho sentimiento. A veces, más de las que me gustaría, hace que me falte el aire y que el mundo se me haga muy pequeño (o incluso demasiado grande). Aparece sin más cuando menos falta hace para destruir cualquier mundo que intentes construir a espaldas de ella. Y lo destruye todo. Destruye emociones positivas para reemplazarlas por negativas. Destruye relaciones. Destruye todo lo que le dejes destruir y no le importa.

Ella, muy a mi pesar, es la ansiedad. Y sigo luchando por hacerla desaparecer, pero parece que quiere estar conmigo mucho más tiempo del que me gustaría. 


\section{ESCRIBIR PARA POLITIZAR, POLITIZAR PARA TRANSFORMAR.}

Aunque mi idea en un principio no contemplaba analizar los relatos, según iba desarrollando el trabajo me he percatado de la necesidad de politizar dichos textos. Esto es que, aunque parece necesario y urgente la escritura creativa en sí como ejercicio de denuncia, considero también muy importante descifrar, deconstruir y atender a los diversos significados que dichos textos puedan poseer entre sus pliegues, siempre interpretándolos desde un marco político y feminista. Por ello, en el presente capítulo realizo una interpretación de los relatos de ansiedad expuestos en el capítulo tres, utilizando como método el denominado "close reading" o "lectura de cerca", para más adelante atender a su relación con el marco teórico expuesto en el capítulo dos. Asimismo, la interpretación de dichos relatos parte desde mi propia experiencia subjetiva, utilizando las herramientas teóricas desarrolladas en el capítulo dos. En ningún momento será mi intención invalidar o juzgar dichos escritos, sino más bien atender a sus diversos significados, prestando especial atención a las encarnaciones y experiencias vivenciales de ansiedad, así como los sentimientos arraigados en el texto, o siguiendo a Ahmed (2004: 13), en la manera en que los textos performan ciertas emociones o sentimientos.

El capítulo se estructura en cuatro apartados, los tres primeros refiriéndose al análisis de cada uno de los tres relatos expuestos en el capítulo anterior. En un cuarto apartado, hago referencia a lo que estos relatos han supuesto para mí en mi propio malestar, y, más generalmente, en mi relación con la ansiedad misma.

\subsection{ANÁLISIS DEL RELATO I: “CiCATRICES VIII”}

En el primer relato, conocí a Boom Baby.

Estaba tumbada en la cama cuando la parálisis le congeló cada músculo ("Había intentado mover los dedos y se había encontrado, de nuevo, paralizada, hechizada por los chillidos burlones (...)”). Se levantó y miró el móvil, pero lo que vio solo le empequeñeció el corazón. Una simple conversación le hizo volver a sentirse pequeña y ahogada; una persona que ya fue, pero que seguía arrastrándola a lugares estrechos, donde no le llegaba el aire y la habitación parecía demasiado pequeña. Incluso para ella. 
El relato de Boom Baby es claro y está compuesto por metáforas, siguiendo una trama limpia que te guía por el relato de un foco a otro. Más que una fantasía parece tratarse de un recuerdo, o de una forma de reconciliarse con él. Por otro lado, la narradora parece haber elegido al personaje (Boom Baby) como una proyección de sí misma, o una forma de hablar del dolor. Este método podría entenderse dentro del marco que planteaba en el capítulo uno, donde mencionaba que hablar de los malestares personales puede traducirse en una experiencia demasiado dolorosa: al proyectarse fuera de sí misma, la distancia le estaría permitiendo escribir. Así, utiliza la imaginación para descubrir y abrazar la verdad, de modo que hablar desde la ficción, desde una proyección, se convierte en una tarea más fácil para paliar con el dolor de escribir sobre un problema o un malestar (Richarson, 1994: 933).

Como he indicado previamente, la autora hace repetida alusión a las metáforas referentes al cuerpo, en el sentido de cómo la ansiedad es representada en el mismo, como si se tratase de un lienzo. La metabolización de las experiencias de ansiedad se representa, como aventuraba en el capítulo dos, mediante un lenguaje concreto, por ejemplo; la presión en el pecho o la dificultad para respirar. En relación a esto, se encuentra el uso de los nombres para referirse a partes del cuerpo; unos suelen relacionarse más a experiencias de ansiedad (pulmones, cuerpo) mientras otros están más relacionados con el amor, o con la relación y las emociones encarnadas (boca, corazón). De esta forma, en el relato puede observarse que en todo momento hace eco de su dolor, como si tratara liberarse de él (el dolor, en este caso, producido por una relación). No obstante, es interesante detenerse ante la romanización del lenguaje, tratando de transformarlo en un discurso capaz de otorgar belleza; una manera más artística de hablar de experiencias que nos atraviesan. Casi da la sensación de que la autora busca una forma de reconciliarse con el recuerdo.

Desde la tercera persona, la narradora habla directamente con la persona que simboliza el foco de la ansiedad misma, como si se tratase de palabras que se hubiesen quedado guardadas en un cajón. A su vez, el lenguaje desplaza la culpa; como si todas las acciones le estuviesen pasando a la protagonista y ella no tuviese control alguno sobre ellas ("eras su talón de Aquiles"), como si los sentimientos fueran autónomos de la conciencia, una lógica que se entiende mejor dentro del orden del amor romántico. Más aún, la autora utiliza los verbos en pasado, casi dando la sensación de querer poner más distancia con la escritura autobiográfica, como un mensaje subliminal para sí misma, un "ya pasó" que todavía no ha surtido efecto. 
Otro factor que llama la atención a simple vista es cómo utiliza adjetivos que se leen como "negativos" desde un primer momento (por ejemplo: "pobre Boom Baby", denotando vulnerabilidad o la fragilidad del personaje, entre otros), mientras que los adjetivos o nombres usados leídos como "positivos" son los que se usan irónicamente o van acompañados de una negativa; es decir, es lo que podría ocurrir pero no ocurre ( "la fiesta de joderle la vida”, “había dejado de ser divertido”, “no tenía gracia”). Así, todas las palabras que en un principio serían positivas, adquieren su sentido negativo mediante la ironía.

Por ello, un sentido de tristeza y nostalgia acompaña durante toda la lectura. No obstante, parece el amor, y no la ausencia del mismo, el motor que mueve el relato en su totalidad ("aunque la angustia no saliera de su cuerpo, ella ese día tampoco consiguió odiarte”). Está presente en toda la escritura, aunque se esconde en los recovecos del dolor, casi romantizando el mismo debido a la forma artística que la narradora tiene de hacer referencia a los dolores ("sentir en toda su gloria el efecto de los golpes"). Además, puede entreverse un anhelo de sentirse arropada y querida, relacionada con la angustia de no serlo, y el acto de despojar de culpa a la otra persona ("Pero, sin querer, tú lo habías vuelto a hacer"). Este acontecimiento resuena en lo que históricamente hemos entendido las feministas como "amor romántico", que ha supuesto y supone para las mujeres una de las vías de sometimiento al régimen hegemónico, una de las materializaciones del "sujeto ideal" que mencionaba en el capítulo dos, y la consecuente angustia o ansiedad al no ser capaces de cumplir con las demandas patriarcales, neoliberales y capitalistas que nos impone la sociedad (tales como el emparejamiento como natural, universal y necesario, la exclusividad, la perdurabilidad de la pareja, la relación de dependencia emocional por parte de las mujeres o el carácter omnipotente del amor, entre otras) (Herrera Gómez, 2010: 294-295).

El texto también puede entenderse bajo el marco de las políticas del miedo que planteaba Ahmed (2004), donde la ansiedad aparece tras el miedo de perder, o, en este caso, dejar ir, una escena (la relación terminada). Este sentimiento de ansiedad surge metabolizado en el cuerpo como una parálisis del sueño en primer lugar ("Había intentado mover los dedos y se había encontrado, de nuevo, paralizada, hechizada por los chillidos burlones y movida como un títere por esa presencia que, otra vez, volvía a sentarse sobre su mejilla, hundiéndole el rostro en la almohada"), agobio ("la habitación se empequeñeció dejándola a ella dentro"), "estrés”, "el pecho cerrado”, "angustia” o presión "entre el corazón y los pulmones", entre otras. Además, otro factor importante 
en el texto es la referencia a la parálisis corporal ("El estrés que llevaba acumulando días, o incluso meses, le corrió por las venas como si fuera pólvora y la parálisis le alcanzó los pulmones") entendido por Berlant (2011) como el "bloqueo": la incapacidad del cuerpo de avanzar o moverse, literal y simbólicamente hablando.

Por último, parece interesante destacar el propio nombre de la protagonista. "Boom" denomina con el acrónimo la acción de cuando algo explota, mientras que "Baby", en inglés, significa, en este contexto, "cariño". La decisión de formar un nombre compuesto de estas dos palabras parece, en primera instancia, una ironía ambivalente de la autora. Por un lado, podría leerse como la explosión de la ansiedad dentro del cuerpo de Boom Baby (proyectado desde la propia autora). Por otro lado, parece formar un último mensaje contra esa misma experiencia, ya que "Boom Baby" puede entenderse, a su vez, como un mensaje de despedida tras una victoria, que pondría fin a lo que sería una partida simbólica (en este caso, una relación).

\subsection{ANÁLISIS DEL RELATO 2: “TERRORES NOCTURNOS”}

En el segundo relato, conocí los terrores nocturnos de María.

El texto se presenta como un reflejo de su día a día, aunque ubicado temporalmente en un momento concreto. Desde la primera línea, el argumento me guía hacia una experiencia concreta ("La última noche que pasó, pensaba que estaba a punto de morir."): la autora sabe lo que quiere contar, y va directa al grano, explicando el proceso previo y posterior. El relato en sí mismo narra cómo reapropiarse de nuestras propias vulnerabilidades, y qué estrategias pueden servirnos para convivir con nuestros dolores y las negociaciones que nos atraviesan.

Para retratar su experiencia utiliza la primera persona del singular, tal vez insinuando que la experiencia del relato se encuentra en algún lugar de su mente, un lugar cuya temporalidad no coincide con la actual. Así, la distancia con la experiencia de dolor está ligada a la temporalidad de la misma y no tiene por qué ir unida al propio autoreconocimiento del texto. En otras palabras, utilizar la primera persona del singular al hablar de experiencias de dolor actuales puede resultar muy complicado, pero si al narrar estamos aludiendo a un momento pasado (por ejemplo, que la escena está basada en un recuerdo), puede hacer de la escritura una práctica más fácil para la autora.

A pesar de ello, en un primer momento la mayor parte de las expresiones utilizadas expresan dolor o vulnerabilidad, además de estar relacionadas con connotaciones 
socialmente entendidas como emociones negativas ("exploté", "deambulaba", “colapsar"). Siguiendo esta línea, María nos guía hacía su propia interpretación de la metabolización de sus experiencias de ansiedad, entre las que me gustaría destacar el insomnio como encarnación de las mismas ("a pesar de no dormir absolutamente nada durante varios días"), pero, además, agobio ("dolor de pecho que pensaba que iba a romperme las costillas"), visiones ("Era un círculo vicioso que llevaba a que a veces tuviera visiones durante el día”) y sensación de ahogamiento ("y una mano en el pecho, tratando de convencer a mi cuerpo de que dejase espacio para respirar"), entre otras. Tomando este último ejemplo, la narradora habla del "respirar" como la última expresión de supervivencia ("y después me estrangulaba sin que yo pudiese coger aire”), o, como señalaba en el capítulo dos, como una "respiración de combate". Siguiendo a Górska, La respiración puede no ser la causa de un ataque de ansiedad, pero forma parte de un conjunto de prácticas corporales que incluyen las tensiones del cuerpo, ya que cuando sufres un ataque de ansiedad, la tendencia es respirar de cierta manera (2016: 270). Así, el mero hecho de respirar bajo semejantes circunstancias se convierte en el mayor éxito posible.

Por otro lado, en el relato también se hace referencia a los quehaceres, a las rutinas diarias que debemos seguir cumpliendo, aunque no se disponga de un estado de salud “correcto" para realizarlas ("Podía hacer todo lo que me pidiesen en la oficina y más, me tomaba un café para acompañar el malestar corporal y volvía al ruedo"). La propia presión social de la que hablaba tanto en el capítulo dos como en el tres, es clave para entender estas dinámicas, donde se ha de aparentar salud mental y tranquilidad para ser reconocida dentro del marco de normas sociales. O lo que es lo mismo: cómo las operaciones del poder estructural y la presión de convertirse en un sujeto ideal, condicionan nuestra vida diaria cuando no nos ajustamos a las normas hegemónicas. La vida sigue, aunque tú no puedas seguir su ritmo, desencadenando un mecanismo de expulsión hacia los sujetos que no se ajusten a las normas hegemónicas. Por ejemplo, en el texto vemos cómo María, a pesar de sus dolores y padecimientos diarios, siente la presión de volver al trabajo, a la vida ordinaria, a pesar de que al hacerlo deba ignorar su propia salud mental. Además, el propio miedo a la estigmatización aparece de forma oculta, pues si admito que tengo un problema (en este caso, una ansiedad crónica que me priva del sueño y, por tanto, de conseguir la productividad que me exige el sistema en el día a día) debo admitir que tal vez necesito ayuda para convivir con él. 
Un factor que no pasa desapercibido y particularmente cobra especial importancia dentro del texto, es la aparición del perro de la protagonista, Dante, que actúa como canalizador de las experiencias de dolor de María ("escucho su corazón a través de la piel y el mío se acompasa a su tranquilo movimiento"). En el relato, puede observarse cómo Dante le acompaña en el proceso de reconocimiento y aceptación, convirtiéndose finalmente en un apoyo emocional que incita a María a pedir ayuda y romper el silencio. Deteniéndome brevemente en esta relación, la autora hace referencia en varias ocasiones a cómo la relación compartida perro-humano permite a Dante ser consciente de los ataques de ansiedad de María ("Supongo que los animales saben leer las emociones humanas mejor que nosotros mismos"). La relación mencionada se convierte en un acto de intimidad y vulnerabilidad compartida, donde precisamente la capacidad de olfato de Dante, como algunos estudios científicos han demostrado (Górska, 2016: 260), le permite leer los sentimientos de su dueña. Siguiendo este planteamiento, dicha relación entre perro y humana da pie a las negociaciones diarias donde la habilidad para responder incluye paciencia, espacio para respirar, y respeto de movimiento, de seguir, de cuidarse (Górska, 2016: 265). Es decir, es a partir de la vulnerabilidad, y más aún, de las continuas negociaciones de la misma, que el vínculo de María y Dante se estructura y fortalece.

Por último, me gustaría destacar del texto que, a pesar de tono general de tristeza y cansancio que lo acompaña, es la reflexión final la que apunta a la esperanza de una convivencia posible con las experiencias vivenciales de ansiedad.

\subsection{ANÁlisis DEL RELATO 3}

En el tercer relato, conocí a la ansiedad como compañera.

La autora comienza hablando de la dificultad que (le) supone hablar sobre "la ansiedad", donde el determinante juega un papel poderoso otorgándole agencia, como un ente propio que opera desligado del sujeto ("nunca me deja sola", "nunca se la he presentado a nadie"). Manifiesta la dificultad que tiene de hablar de "ella", dificultad que se hace más presente a lo largo del texto.

En el primer párrafo, la autora trata de ubicarla en un lugar físico o corporal, aludiendo vagamente a las metabolizaciones de la misma en su propio cuerpo ("Tampoco sé dónde está, ¿en mi mente? ¿en mi pecho? ¿en mi garganta?”), para más adelante aludir a las operaciones corporales y psíquicas de la ansiedad en su presente, y aún más relevante: cómo su presencia le hace sentirse avergonzada. A pesar de no ahondar más 
profundamente en el tema, es necesario que recalque que la ansiedad entendida como vergüenza es un factor crucial a la hora de entender la invisibilización de la misma, pues algo que no está socialmente aceptado es algo que deberá mantenerse oculto. De esta forma, podemos entender "la vergüenza" como concepto ambivalente que se teje entre las dinámicas de resistencia y la sumisión a la norma, ya que se trata de una emoción que ordena y organiza las relaciones sociales (por ejemplo, aceptar la ansiedad puede suponer un mecanismo performativo, mientras que aceptar esa vergüenza y acatarla supondría obedecer las normas hegemónicas de subjetividad adecuada).

El texto prosigue relatando cómo la ansiedad encontró a la narradora y no al revés, para más adelante centrarse en lo que "ella" es y en lo que "ella" hace. En su historia, sin embargo, no existen personajes más allá de "la ansiedad" como compañera y la reflexión de la autora; es ella misma y su necesidad de explicar lo caótico, lo que a su juicio no posee de una razón o estructuración clara, pero sin embargo es lo que a la larga condiciona su forma de vivir. Además, llama a la atención que el texto esté dispuesto en primera persona del singular, es decir, desde la propia visión de la autora (al contrario, por ejemplo, que el primer relato), de ese modo asumiendo la responsabilidad no sólo de verse reflejada, sino también de contar en primera persona sus experiencias vivenciales.

Por otra parte, la estructuración del texto está plagado de negativas en cuanto a lo que la autora hace o piensa ("no sé”, "tampoco sé”, "nunca más podría controlar nada”, etc.), como si todo resultase en un gran interrogante o una profunda incertidumbre. De esta forma, la ansiedad se presenta como algo inevitable, algo que encuentra o actúa sobre el sujeto sin posibilidad de impedimento ("me encontró", "me pilló", "hace que me falte el aire", "se me haga", entre otras): así, la ansiedad es tratada como un ente que simplemente está, una realidad en la que, a ojos de la narradora, no se puede cambiar.

Es interesante hilar esta parte del relato con las teorías de la dicotomía éxito/fracaso de las que hablaba en el capítulo dos, ya que la ansiedad y la organización en la que la sociedad está establecida, hace pensar que las personas que sufren ansiedad están "rotas", o, en definitiva, son susceptibles de ser "arregladas". Como explicaba en el capítulo dos, esta concepción es problemática porque responde a las normas hegemónicas establecidas de lo que debería ser una subjetividad adecuada (Górska, 2016); es decir, un sujeto hegemónico, blanco, heterosexual, exitoso (nótese que el masculino nunca será genérico en este trabajo), y por supuesto, libre de enfermedades mentales. Las resistencias combativas (también mencionadas en el capítulo dos) son clave a la hora de oponer una 
resistencia contra estas normas, reivindicando otras formas de vivir y moverse lejos de las normas establecidas y las operaciones del poder estructural.

Otro aspecto que me gustaría destacar se refiere a la dificultad del (auto)reconocimiento ("ni tan siquiera sabía cómo se llamaba. Incluso llegué a dudar si existía o si simplemente me estaba volviendo loca"), de la que hablaba particularmente al inicio del capítulo tres. El lenguaje es un factor fundamental a la hora de reconocer y señalar las dinámicas que nos oprimen, y si algo sabemos desde el feminismo es que "lo que no se nombra no existe", por lo que parece imposible hablar de ansiedad si esa presión en el pecho o esa falta de aire no se categoriza. Precisamente por esto, uno de los factores más importantes de este trabajo en poner en valor las experiencias de ansiedad, denominándolas como tal, porque no será la primera ni la última vez que alguien pueda reconocer sus dolores tras verlos o leerlos de otra persona.

Por otro lado, la autora hace mención a la experiencia corporal de la ansiedad aludiendo especialmente a la falta de aire y sensación de agobio. Además, me gustaría destacar la referencia a las emociones "positivas" y "negativas" ("Destruye emociones positivas para reemplazarlas por negativas"), reflexionando cómo en el propio relato se dan por sentadas; el dolor entendido como una emoción o sentimiento negativo contra la dualidad de la felicidad como emoción o sentimiento positivo. La dicotomía se cristaliza en el juego de palabras que arma más adelante: destruir versus construir (“...para destruir cualquier mundo que intentes construir a espaldas de ella. Y lo destruye todo"). Destruir como materialización de la desesperanza y sinónimo de ansiedad; de nuevo, como si no hubiese acción posible para impedir tal malestar. Y construir, como esfuerzo último de resistencia contra esa materialización.

Por último, desde mi posición como lectora, percibo en el relato un profundo malestar y sentimiento de tristeza. Yendo un poco más allá, el cansancio, tanto corporal como mental, también parece uno de los motores de la lectura. Este cansancio también habita en el tono general en el que el relato está escrito, donde se puede percibir en la ausencia de otras estructuras verbales más complejas: es un lenguaje del cuerpo, de casa, que aborda unos sentimientos tan enredados en la persona que a veces resultan difíciles de observar. 


\subsection{REFLEXIONES FEMINISTAS: El AlCANCE DE LOS RELATOS.}

No quería terminar este capítulo sin antes referirme brevemente a lo que estos relatos en particular, y la escritura en general, han supuesto en mi propia relación con la ansiedad. Empezaré diciendo que en un primer momento no me sentía digna de escribir un apartado siquiera parecido a este, y que la idea de realizarlo me ha traído mucha incertidumbre, tal vez porque no he pretendido en ningún momento hacer de este trabajo algo sobre mí o mi propia experiencia, o tal vez porque la propia ansiedad tiende a colarse asiduamente entre los recovecos de mi cabeza. No obstante, la propia lectura de los relatos me ha enseñado a valorar mi propia experiencia dentro de este trabajo de investigación, y, como aventuraba en el capítulo uno, como persona que está su vez produciendo conocimiento. No me daba cuenta de que desplazar el sujeto de estudio no implica a su vez ignorar mis propias vivencias, por eso mismo, este trabajo es de algún modo el proceso, la puesta en práctica o el comienzo de mí misma hablando del fenómeno que me paraliza el cuerpo.

Creo que lo más importante que han conseguido los relatos es el sentimiento de complicidad y colectividad. Por todo lo que he explicado a lo largo de esta investigación, la ansiedad es, ante todo, solitaria, y nunca te das suficiente cuenta de lo necesario que es compartir tus malestares, quizás hasta que ya son tan profundos que tú misma los acabas aislando. Por esto, el sentimiento de sororidad y apoyo que me produce leer los relatos de mis compañeras resulta clave en mi lectura, ya que de algún modo me hace sentir más cerca de ellas, y a la vez más cerca de comprender mis propios mecanismos y vivencias.

Otro punto que me ha llamado especialmente la atención, es el reconocimiento de la materialización. Esto es, que como he expuesto incansablemente a lo largo del trabajo, cada persona tiene sus propias materializaciones de la ansiedad, pero no había parado a pensar que, en mi propio imaginario, la mía se presenta como un monstruo que habita en mi cabeza. A veces está escondida y espera, pero cuando me siento cansada o triste no tiene necesidad de llamar a la puerta, simplemente aparece y se hace grande. A partir de ahí podría compararla con una bola de nieve: cuanto más avanza, más se hincha, y más difícil es devolverla a su estado natural. De algún modo, el leer factores clave en otras experiencias me hace repensar, validar y reconocer otras en mis propias vivencias, un proceso urgente y necesario para empezar a combatir nuestros malestares.

Por último, estos relatos me hacen sentirme más cerca de mis compañeras, y a la vez más motivada a seguir en este proceso de investigación. Simplemente por eso, 
considero que el trabajo ha cumplido con lo que pretendía, más allá de los objetivos científicos; unir, repensar, validar, politizar. Lo que me produce es un sentimiento más profundo, de cercanía, de lazos que se estiran pero no se rompen, de las luchas individuales que pasan a ser colectivas, y de la esperanza que traen consigo. 


\section{CONCLUSIONES:}

\section{COLECTIVIZAR LOS MALESTARES, COMPARTIR NUESTRAS VIVENCIAS.}

Como decía al principio de esta investigación, en esta tesis de máster no he pretendido, en ningún momento, encontrar una respuesta última y objetiva con respecto a las experiencias de ansiedad. Más bien, ofrecer un espacio donde esas experiencias tuvieran cabida era mi objetivo principal, un espacio en el que pudieran interrelacionarse y dialogar con las teorías feministas que he decidido incorporar en el trabajo, como un proceso de aprendizaje más que un proyecto auto-conclusivo. También me parece importante recalcar que ceder de algún modo este espacio supone reconocer a su vez que parto de una situación privilegiada que me permite hacerlo, y en ningún caso como muestra de paternalismo o elitismo: soy consciente de mi realidad y he decidido usarla para poner en diálogo un fenómeno, como he explicado, silenciado y utilizado como dispositivo de organización y jerarquía social. Dicho esto, en este último apartado me gustaría reunir algunas de las reflexiones que han tenido cabida en esta investigación, tanto directamente como transversalmente, para recapitular de alguna manera todo aquello sobre lo que he trabajado.

En primer lugar, con este trabajo refuerzo la idea de la importancia de la experiencia como fuente de conocimiento válida dentro del campo de las ciencias sociales (y, más aún, feministas). Más particularmente, con métodos como la autoetnografía o la escritura creativa he pretendido reivindicar la importancia de los saberes subjetivos, ya que es innegable que la experiencia, específicamente la experiencia de las mujeres, ha sido erradicada históricamente. Partir de nuestros cuerpos, entonces, parece urgente y necesario dentro de la agenda feminista, por lo que fortalecer una noción como la validez de la experiencia es irrefutable.

En segundo lugar, retomo la previa mención a la escritura creativa, ya que me resulta importante recalcar la necesidad de utilizar métodos no convencionales para la producción de conocimiento. La escritura creativa ha resultado un método muy enriquecedor, ha aportado claves cruciales a la hora de abordar política y socialmente un fenómeno como la ansiedad, visibilizando emociones y sentimientos encarnados en 
dichas experiencias que no me habría sido posible abordar de haber utilizado métodos mejor aceptados en la investigación social. La escritura en sí (y no sólo el análisis de la misma) por tanto, se ha traducido en una herramienta poderosa para deshacer el silencio, convirtiéndose a su vez en un ejercicio de autoconocimiento y aceptación.

En tercer lugar, las políticas occidentales neoliberales (y en particular, las políticas del miedo y el fracaso) elaboran continuamente dispositivos y dinámicas sociales con el objetivo de mantener jerarquías y (re)producir sujetos que se ajusten a los ideales sociales. De esta forma, las políticas neoliberales como el miedo o el fracaso suponen un método de socialización que dicta lo que se debe y lo que no se debe de ser, y las experiencias de ansiedad pueden leerse como resistencias combativas ante esta demanda de subjetividad "adecuada". En otras palabras, no (re)producir o reconocerse en dichas dinámicas hegemónicas puede, en muchas ocasiones, convertirse en malestares o padecimientos corporales. No obstante, en es en este estado de vulnerabilidad donde podemos performar actos de resistencias efectivas contra las operaciones del poder estructural que nos ahogan y silencian día tras día.

En cuarto lugar, no es posible entender las experiencias de ansiedad sin su metabolización o encarnación corporal. En otras palabras, las experiencias de ansiedad no pueden ser entendidas como un ente separado del cuerpo, por lo que es urgente y necesario comenzar a entenderlas en relación al mismo. A su vez, cada una de estas experiencias es subjetiva y diversa, por lo que es problemático pensar que la ansiedad es una y debe "corregirse" de forma individual. Por un lado, porque pensar en "corregir" dichos estados atiende a las demandas neoliberales previamente mencionadas; por otro lado, individualizar el concepto de ansiedad hace que nos alejemos de unas resistencias colectivas, aquellas que ponen el foco en el poder estructural, y nos centremos en la responsabilidad del propio sujeto.

En quinto lugar y muy relacionado con esto último, las coaliciones feministas y su agenda política, social y económica, me llevan a recalcar que mientras aún es importante prestarle atención a la idea de "respirar" individualmente, es necesario plantearse, a su vez, la noción de "conspirar" en compañía. Esta idea de "conspirar" colectivamente resulta una noción clave, pues es necesario empezar a plantearse la salud mental, y particularmente la de las mujeres, como un problema estructural de carácter neoliberal y capitalista que debe abordarse desde una perspectiva que reconozca y atienda esta idea. Es decir, es necesario entender que nuestra felicidad deviene socialmente de si cumplimos o no con las normas e ideales hegemónicos establecidos, operaciones del 
poder estructural, y no como un problema individual que sólo podrá enmendarse de forma individual (de esta forma responsabilizando al sujeto y estigmatizándolo).

En sexto lugar, la necesidad de desestigmatizar las enfermedades mentales, entre las que se encuentran la ansiedad y la depresión, es materia urgente; darles nombre no con el objetivo de normalizarlas, sino de reivindicarlas y entenderlas desde una perspectiva feminista que nos permita habitarlas de formas alternativas, con el fin de reapropiarnos de nuestros propios cuerpos. Para ello, es necesario atender diversos aspectos relacionados con el lenguaje, por ejemplo, ya que supone un arma interesante que puede utilizarse como herramienta contra la estigmatización o, por el contrario, como herramienta para la reproducción de las discriminaciones sociales. No sólo importa lo que decimos, sino también lo que no decimos.

Por último, me gustaría concluir con esperanza. Los espacios feministas resultan cruciales a la hora de compartir y repensar nuestros dolores y padecimientos, y de algún modo, nos animan a colectivizar nuestras luchas y no sentirnos solxs. Si bien es cierto que no podemos dar por sentado que los espacios feministas sean, por definición, espacios libres de juicios, sí podemos pensar que parten de una base crítica que está en continuo aprendizaje. Por lo que disponer de espacios de escucha y sororidad desde donde nombrar, reconocer y combatir las dinámicas de poder que nos asfixian, resulta una idea crucial que debe entrar en la agenda política, económica y social feminista.

Tu guerra es mi guerra, y en esto, compañerx, estamos junxs. 


\section{BIBLIOGRAFÍA}

Ahmed, S. (2004). The Cultural Politics of Emotion. Edinburgh: Edinburgh University Press.

Ahmed, S. (2012). The Promise of Happiness. Durham: Duke University Press.

Ahmed, S. (2017). Living a Feminist Life. Durham: Duke University Press.

Allen-Collinson, J. (2012). Autoethnography: situating personal sporting narratives in socio-cultural contexts. En K. Young, \& M. Atkinson, Qualitative Research on Sport and Physical Culture (págs. 191-212). Bingley, UK: Emeral.

Anderson, K. N., Jeon, A. B., Blenner, J. A., Wiener, R. L., \& Hope, D. A. (2015). How People Evaluate Others With Social Anxiety Disorder: A Comparison to Depression and General Mental Illness Stigma. American Journal of Orthopsychiatry, 131-138.

Aubecht, K. (2012). Disability Studies and the Language of Mental Illness. Review of Disability Studies: An International Journal.

Berlant, L. (2011). Cruel Optimism. Durham: Duke University Press.

Butler, J. (2006). Vida Precaria. Buenos Aires: Paidós.

Cabruja i Ubach, T. (2007). Violencias de la psicología a las mujeres: psicologización, psicopatologización y silenciamiento. En B. B. Martín, Estado de wonderbra. Entretejiendo narraciones feministas sobre las violencias de género (págs. 155171). Bilbo: Virus Editorial.

Cvetkovich:, A. (2012). Depression: A Public Feeling. Durham: Duke University Press.

Das, V. (2008). Antropologías del dolor. En V. Das, Sujetos del dolor, agentes de dignidad (págs. 409-437). Colombia: Universidad Nacional de Colombia. 
Esteban, M. L. \& Távora, A. (2008). El amor romático y la subordinación social de las mujeres: revisiones y propuestas. Anuario de Psicología, 59-73.

Fanon, F. (1967). Algeria Unveiled. En F. Fanon, A Dying Colonialism (págs. 35-67). New York: Grove Press.

García López, D. J. (2017). El fin de todos los derechos: El cuerpo viviente como umbral de la democracia. Anales de la Cátedra Francisco Suárez, 223-247.

Gregorio Gil, C. (2014). Traspasando fronteras dentro-fuera: Reflexiones desde una etnografía feminista. Revista de Antropología Iberoamericana, 297-322.

Górska, M. (2016). Breathing Matters: Feminist Intersectional Politics of Vulnerability. Linköping: Linköping University.

Halberstam, J. (2011). The Queer Art of Failure. Durham: Duke University Press.

Haraway, D. (1988). Situated Knowledges: The Science Question in Feminism and the Privilege of Partial. Feminist Studies, , 575-599.

Herrera Gómez, C. (2010). La construcción sociocultural del amor romántico. España: Editorial Fundamentos.

hooks, b. (1991). Theory as a Liberatory Practice. Yale Journal of Law \& Feminism, 4. Mbembé, A. (2003). Necropolitics. Public Culture, 11-40.

Medina Doménech, R. M. (2012). Sentir la historia. Propuestas para una agenda de investigación feminista en la historia de las emociones. ARENAL, 161-199.

Perera, S., \& Pugliese, J. (2011). Introduction: Combat Breathing: State Violence and the Body in Question. Somatechnics, 1-14.

Pérez Arias, M. (2019). Mapeando la ansiedad en la academia: Una aproximación desde las políticas del miedo y la respiración de combate. En M. Vagalume, L. Asué Mbomio, M. Pérez Arias, C. Aparicio Villalonga, S. Agüero Fernández, R. M. 
García, \& R. Cobo Bedia, Disidencia en el Cuerpo: Perspectivas Feministas (pág. 25 - 40). Madrid: Ménades.

Rich, A. (1987). Notes Towards a Politics of Location. En A. Rich, Blood, Bread and Poetry (págs. 210-232). London: Virago.

Richardson, L. (1994). Writing: A method of inquiry. En N. K. Denzin, \& Y. S. Lincoln, Handbook of qualitative research (págs. 516-529). CA: Thousand Oaks.

San Martín, C. (2007). Discursos psicológicos difíciles de digerir o en torno a la psicopatologización generizada de los malestares. En B. B. Martín, Estado de wonderbra. Entretejiendo narraciones feministas sobre las violencias de género (págs. 155-171). Bilbo: Virus Editorial.

Scott, J. W. (1991). The evidence of Experience. Critical Inquiry, 773-797.

Uribe Restrepo, M., Mora, O. L., \& Cortés Rodríguezz, A. C. (2007). Voces del estigma. Percepción de estigma en pacientes y familias con enfermedad mental. Universitas Médica, 48(3), 207-220.

Visser, S. B. (2018). Trauma Ordinariness: Tracing the Everyday Experience of Trauma trough Two Encounters, Four Memoirs. Utrecht University, Utrecht. 